\title{
Molecular-Imprinting-Based Surface-Enhanced Raman Scattering Sensors
}

\author{
Xiaotong Guo, Jinhua Li,* Maryam Arabi, Xiaoyan Wang, Yunqing Wang,* and Lingxin Chen*
}

Cite This: ACS Sens. 2020, 5, 601-619

Read Online

ACCESS | Lill Metrics \& More | 回 Article Recommendations

ABSTRACT: Molecularly imprinted polymers (MIPs) receive extensive interest, owing to their structure predictability, recognition specificity, and application universality as well as robustness, simplicity, and inexpensiveness. Surface-enhanced Raman scattering (SERS) is regarded as an ideal optical detection candidate for its unique features of fingerprint recognition, nondestructive property, high sensitivity, and rapidity. Accordingly, MIP based SERS (MIP-SERS) sensors have attracted significant research interest for versatile applications especially in the field of chemo- and bioanalysis, showing excellent identification and detection performances. Herein, we comprehensively review the recent advances in MIP-SERS sensors construction and applications, including sensing principles and signal enhancement mechanisms, focusing on novel construction strategies and representative applications. First, the basic structure of the MIP-SERS sensors is briefly outlined. Second, novel imprinting strategies are highlighted, mainly including multifunctional monomer imprinting, dummy template imprinting, living/controlled radical polymerization, and

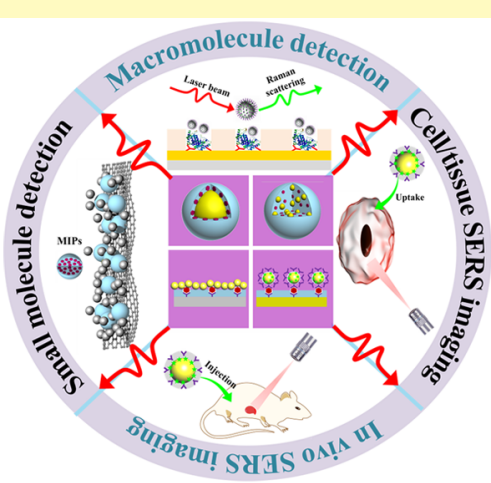
stimuli-responsive imprinting. Third, typical application of MIP-SERS sensors in chemo/bioanalysis is summarized from both small and macromolecular aspects. Lastly, the challenges and perspectives of the MIP-SERS sensors are proposed, orienting sensitivity improvement and application expanding.

KEYWORDS: molecular imprinting, surface-enhanced Raman scattering, sensor, molecularly imprinted polymers, construction strategy, applications, challenges, perspectives

Urface-enhanced Raman scattering (SERS) is an ultra$\checkmark$ sensitive vibrational spectroscopy technique for analyte characterization and determination, with the distinguished features of fingerprint recognition, high resolution, strong antiinterference ability, and nondestructive property to samples. ${ }^{1-3}$ Even compared with its biggest competitor of fluorescence spectroscopy, SERS is superior to fluorescence in three main aspects: (1) better photostability, competently resisting photodegradation and photobleaching, ${ }^{4-6}$ (2) narrower spectral widths, relieving the spectral peak overlapping problem between different substances and improving multiple detection ability, ${ }^{7}$ and (3) wider types of detectable analytes, since in principle the Raman signal of any substance with Raman activity can be enhanced when it locates in a hotspot region. ${ }^{8}$ Consequently, SERS has drawn much attention for versatile applications, especially playing an increasingly important role in chemo- and bioanalysis. However, SERS still faces two major challenges at the current stage. The first is designing targets capturing interfaces. ${ }^{9}$ SERS occurs only when the targets are very close to the SERS substrate surface. ${ }^{10}$ Thus, researchers modified various kinds of capturing units on the substrates, including antibodies, ${ }^{11}$ aptamers, ${ }^{12,13}$ small molecules, ${ }^{14,15}$ and ion ligands, ${ }^{16,17}$ imparting the surface selective capturing ability toward different types of targets. The second is resisting the matrix interference. ${ }^{18}$ In real-sample analysis,
SERS substrates are usually inactivated due to unspecific adsorption by the interferences. ${ }^{18}$ To avoid this problem, the uncovered SERS substrate surface by the capturing units was blocked by linear, long-chain polymers such as poly(carboxybetaine acrylamide). ${ }^{19}$ The polymers can prevent interference molecules from approaching the metal surface thus reduce target signal fluctuations. Despite the feasibility of the above methods having been proven by a few proof-ofconcept research studies, these methods are hard to popularize because of the limited types, high cost, and instability of the modification agents. Therefore, it is still highly demanded and a great challenge to develop versatile ways to prepare such SERS substrates with both high detection sensitivity and excellent capture selectivity.

Molecularly imprinted polymers (MIPs), prepared by mimicking the interaction between receptors and antibodies in nature, possess characteristic capture selectivity, with tailor-

Received: October 17, 2019

Accepted: February 19, 2020

Published: February 19, 2020 


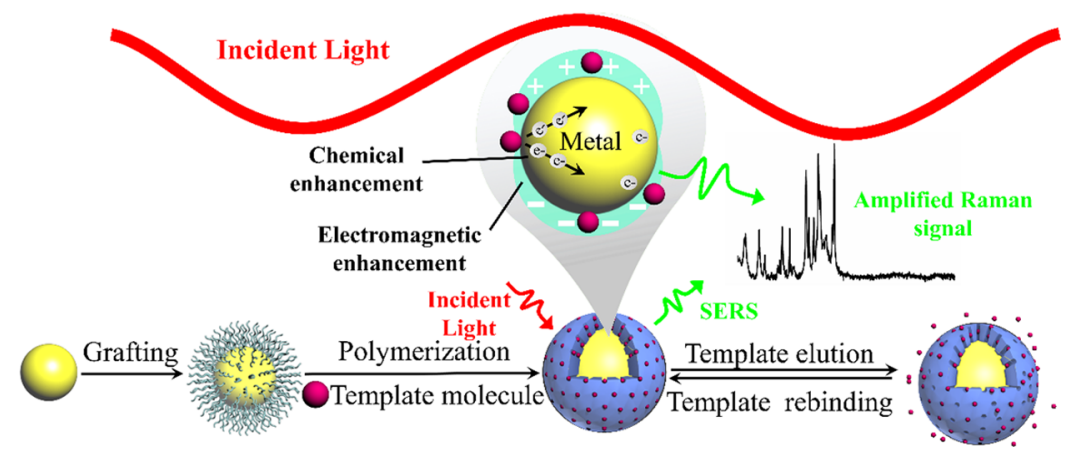

Figure 1. Schematic of MIP-SERS sensors construction and enhancement principle.

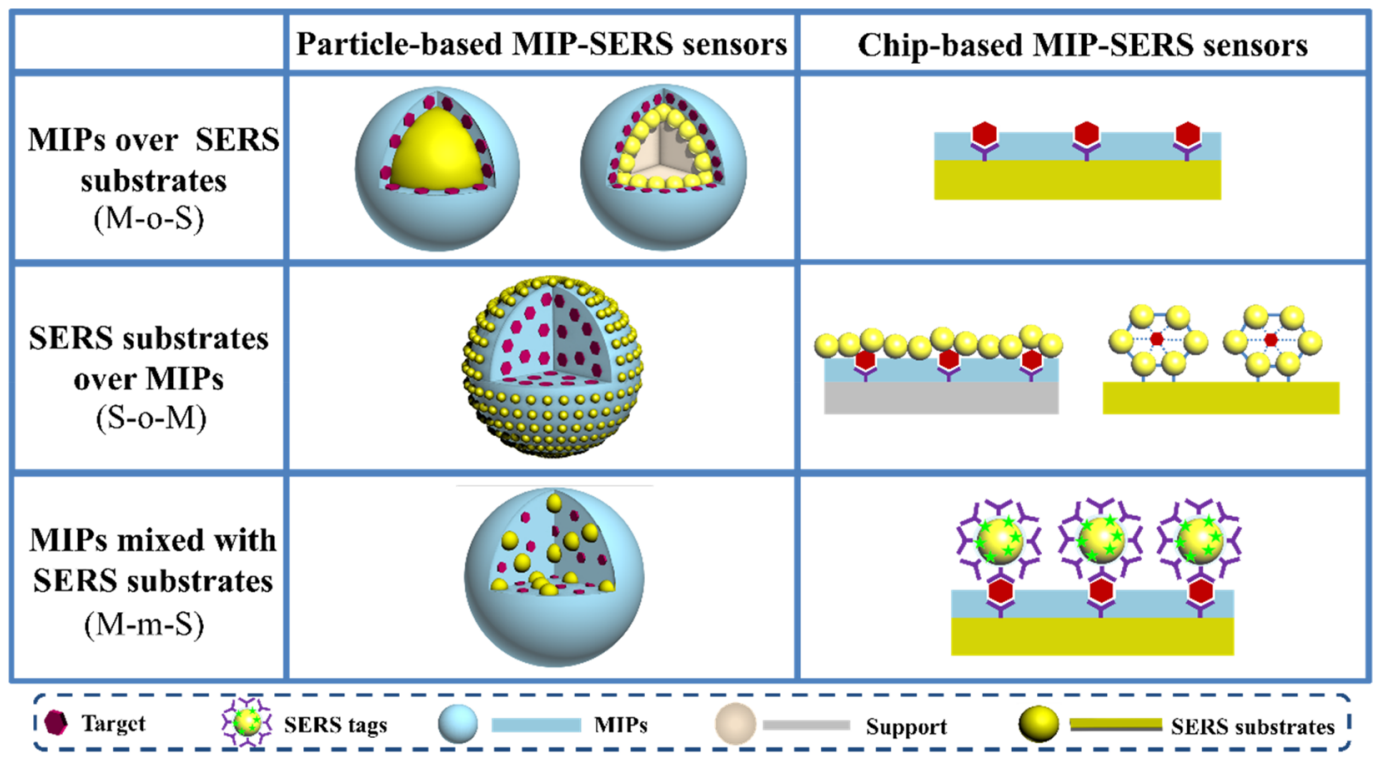

Figure 2. Schematic of the common structure for MIP-SERS sensors.

made binding sites complementary to the template molecule in shape, size, and functional group. ${ }^{20,21}$ MIPs possess excellent selection and recognition ability similar to traditional antibodies but with much better structure stability. ${ }^{22,23}$ In addition, MIPs are prepared by relying on covalent/noncovalent bonds between common functional monomers and the target molecules, making them general materials capable of the capture of a wide variety of targets. ${ }^{24-26}$ Owing to the three major features of structure predictability, recognition specificity, and application universality, MIPs have been broadly applied in various fields, mainly including sample pretreatment, ${ }^{27-29}$ chromatographic separation,,$^{30,31}$ and chemical/ biological sensing. ${ }^{32,33}$ Among them, the sensing applications of MIPs, namely, MIP-based sensors, have attracted increasing interest, in which the MIPs as recognition elements can specifically bind target analytes and as transduction elements can generate output signals for detection. ${ }^{26}$ Especially, MIP based SERS sensors (MIP-SERS sensors) have attracted sustainably increasing interest, since the employment of MIPs endows SERS with excellent capture selectivity and thereby greatly improves the analytical performances of the sensors. $^{34-36}$

In general, traditional MIP-SERS sensors are composed of SERS substrates and MIP layers decorated on the substrates. The basic construction process and enhancement principle and sensing mechanism are schematically shown in Figure 1. As seen, first, SERS substrates are synthesized and modified; next, the precomplex between target compounds (or similar-target compounds) as template molecules and functional monomer is produced. The monomers are oriented or aligned around the template molecules by covalent or noncovalent interaction to form molecular aggregates. Then, cross-linkers are added to cross-link the monomer molecules by polymerization, so that the interaction between the template molecules and the functional monomers is retained. Finally, the template molecules are removed, leaving "holes" complementary to the spatial structure of the template molecules. These "holes" render the MIP-SERS sensors with "memory" function, which can selectively capture target molecules to the metal surface for SERS generation under the excitation of the incident light. ${ }^{37}$

It is well-known that noble metal particles determine the enhancement factor. Generally, nanoparticles (NPs) with tips or sharp edges, such as nanorods, ${ }^{20}$ nanowool balls, ${ }^{38}$ nanostars, ${ }^{39,40}$ nanoflowers, ${ }^{21}$ and nanosheets, ${ }^{41}$ have better Raman enhancement ability and are popular in SERS substrate fabrication. ${ }^{10,42}$ The distribution pattern of the NPs is also a critical factor. ${ }^{20,43-51}$ The distance between them needs to be less than $10 \mathrm{~nm}$ to achieve a strong electromagnetic field (hotspot). ${ }^{52}$ When the molecules fall into the "hot spot" area, the Raman signal will be greatly enhanced, ${ }^{53,54}$ thus rendering the sensors with satisfactory detection sensitivity. Moreover, the NP distribution uniformity is also required to ensure the 
signal repeatability of different detection sites from a single sensor. ${ }^{55}$

There are two main detection modes for MIP-SERS sensors. The label-free mode is suitable for the analytes of strong Raman signals such as molecules with large chromophores. ${ }^{56,57}$ The identification and quantification can be achieved directly by their own signals. ${ }^{53,58}$ In contrast, the signals of molecules with small cross sections cannot be directly monitored. ${ }^{10,59-61}$ Therefore, SERS probes with high sensitivity and specific Raman signatures are also involved in qualitative and quantitative detections as a label mode.

In 2003, Wulff et al. reported the first MIP-SERS sensor, achieving the detection of D-dibenzoyltartaric acid and $\mathrm{N}$ benzyloxycarbonyl aspartic acid. ${ }^{36}$ In the past decade, MIPSERS sensors have received increasing interests and gained blooming development from sensor construction strategy to applications. Therefore, herein, we propose to comprehensively review the latest advances in MIP-SERS sensors and discuss the challenges including (1) the integration of MIPs with SERS substrates and controlling the interface properties, (2) ensuring higher imprinting capacity under the premise of SERS activity, and (3) improving the detection sensitivity of MIP-SERS sensors. Then, we introduce some highlighted, practical applications in the field of chemical and biological analysis. Finally, the prospects are presented from the aspect of the rapidity and miniaturization detection.

\section{STRUCTURES OF MIP-SERS SENSORS}

MIP-SERS sensors can be divided into particle-based and chipbased types based on the sensor sizes and application scenarios. Both of them can be further separated into three subcategories according to the relative positions of the SERS substrates and the MIPs, i.e., MIPs over SERS substrates (M-oS), SERS substrates over MIPs (S-o-M), and MIPs mixed with SERS substrates (M-m-S), as shown in Figure 2. The advantages and disadvantages of different structured MIPSERS sensors are listed in Table 1.

Particle-based MIP-SERS sensors are suitable for detection in solutions due to the good dispersibility. In a particle-based M-o-S sensor, single plasmonic NPs (such as nanosphere ${ }^{38}$ or nanoshell with built-in hotspot ${ }^{46,49}$ ) are usually used as the SERS substrates, and the MIPs layer is grafted/coated on the NPs by surface imprinting. This structure has favorable masstransfer and sorption kinetics. The crux to constructing this sensor is tightly bonding the MIPs on the NPs surfaces and controlling the thickness of MIPs. ${ }^{20,47}$ In a particle-based S-o$\mathrm{M}$ sensor, multiple metal NPs are involved to generate the "hot spot" effect, which is advantageous to improve the sensitivity. ${ }^{62}$ However, it often suffers from drawbacks of poor mass transfer and background interference from MIPs. The vitality to build this structure is to effectively control the size and the amount of metal NPs to take a balance of the positive "hot spot" effect and the negative "light shielding" effect. An M-m-S mixing sensor $^{50}$ is more easily prepared compared with the former, which avoids complex grafting of the SERS substrates. However, it has relatively low mass transfer and sorption kinetics, and the size of the MIPs should be controlled to avoid template leakage. $^{45}$

The chip-based MIP-SERS sensors are developed for in situ, fast detection applications. ${ }^{63-67}$ The preparation and sensing principles are similar to that of the particle-based sensors. A main difference is that the chip-based MIP-SERS sensors have a larger surface area, which enables them to combine with

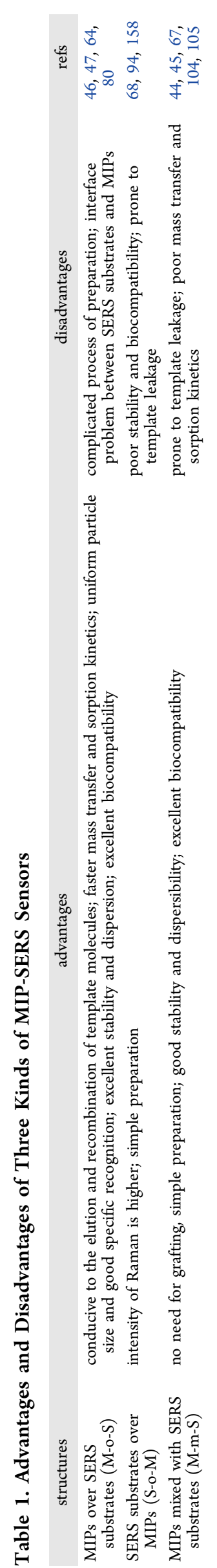




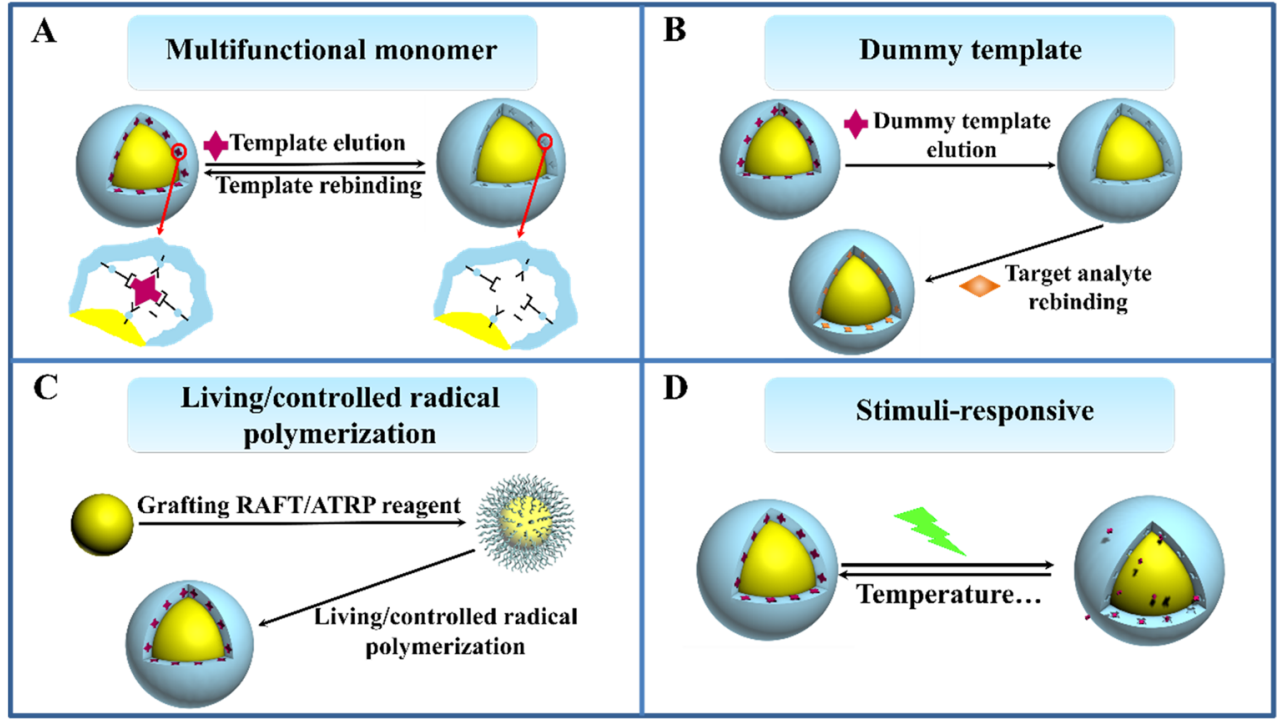

Figure 3. Schematic of new construction strategies for MIP-SERS sensors.

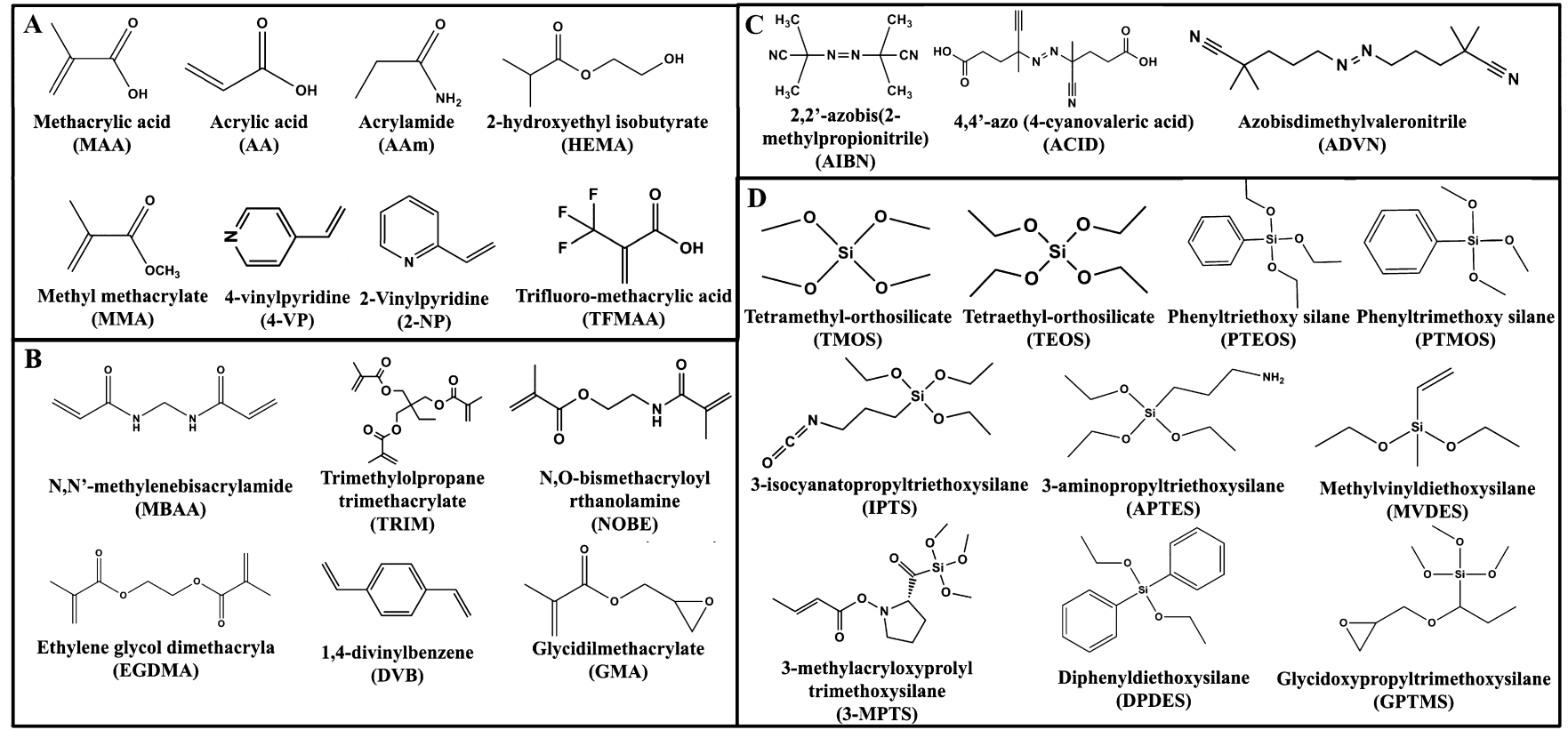

Figure 4. Structural formulas of commonly used functional monomers (A), cross-linkers (B), initiators (C), and polymerization precursors for solgel processes (D).

SERS tags to develop sandwich MIP-SERS sensors for Raman inactive macromolecule detection via a labeling mode. ${ }^{67,68}$

\section{CONSTRUCTION STRATEGIES OF MIP-SERS SENSORS}

As seen above, with the transition from single/multiple particles to chips, various SERS substrates have been easily attained based on gradual mature preparation technologies. Therefore, at this stage, the performances of MIP-SERS sensors are determined by some key factors in related to MIPs preparation. Most difficulties in the construction process of MIP-SERS sensors can be alleviated or overcome by designing and synthesizing excellent MIPs. Four major construction strategies of MIP-SERS sensors have been developed. As illustrated in Figure 3, (A) multifunctional monomer imprinting for improving capture selectivity, (B) dummy template imprinting for improving accuracy and expanding detection analytes, (C) living/controlled radical polymerization for increasing sensitivity, and (D) stimuli-responsive imprinting for intelligent detection have greatly improved the analytical properties and widened the application areas of MIPSERS sensors. Commonly used functional monomers (A), cross-linkers (B), initiators (C) and polymerization precursors (D) are listed in Figure 4.

Multifunctional Monomer Imprinting for Improving Capture Selectivity. The selection of a functional monomer is crucial to prepare ideal MIPs, because the appropriate interaction between the template molecule and functional monomer guarantees excellent selectivity and stability of MIPs. ${ }^{69-71}$ Multiple-point interactions between templates and monomers increase the binding sites in MIPs, usually through multiple noncovalent bonds or the combination of 
A
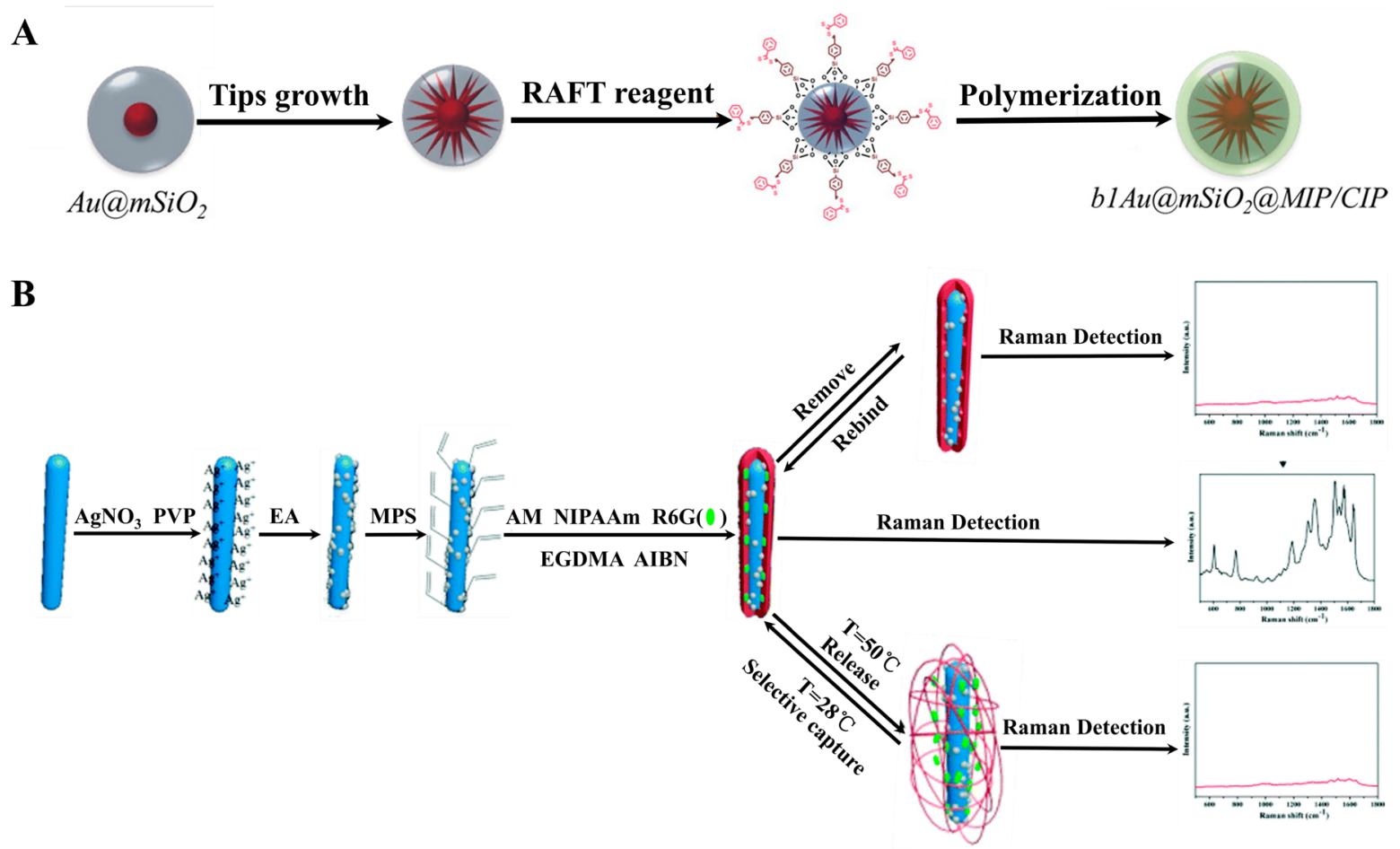

Figure 5. (A) Schematic illustration for the preparation of "star-shaped" branched gold-silica-MIP (b1Au@mSiO $\mathrm{AMIP}_{2}$ by using the branching-functionalization-polymerization approach. Adapted with permission from ref 39. Copyright 2016 American Chemical Society. (B) Schematic illustration for the preparation of ZOA-TMIPs and the shrinking/swelling behavior in the SERS detection of R6G upon specific recognition. Adapted with permission from ref 83. Copyright 2017 Royal Society of Chemistry.

covalent and noncovalent bonds, and effectively enhance the selectivity of MIPs based sensors. Therefore, the combined use of two or more functional monomers complementary to different regions of the template molecule, namely, multifunctional monomer imprinting (Figure 3A), has become an effective construction strategy for MIP-SERS sensors endowed with high capture selectivity and recognition capability via the synergy of multiple functional monomers.

Carboni et al. ${ }^{72}$ have used the mixed functional monomers of tetraethoxysilane and 1,8-bis(triethoxysilyl) octane with the ratio of 1:1 (molar ratio) to prepare a MIP-SERS sensor for the detection of paraoxon. This combination offers the best compromise between the stability (thermal and hydrolytic stability), surface hydrophilicity, and capture selectivity of the MIP-SERS sensor, while other combinations have the problems of difficult elution and poor stability. Liu et al. ${ }^{73}$ have synthesized a MIP-SERS sensor by using a boronic acid functionalized substrate with four silylating monomers. Among them, boronic acid-functionalized substrates can interact with template molecules through covalent bonds, while the four functional monomers can interact with template molecules at different locations through noncovalent bonds (electrostatic attraction, hydrogen bonding and hydrophobic interaction) to achieve directional imprinting for targets. So, the sensor shows high binding affinity to the target glycoproteins with a high imprinting factor (IF) of 5.8.

The multifunctional monomer imprinting strategy has contributed greatly to attain highly selective and stable MIPSERS sensors for various analytes such as the macromolecules of glycoproteins ${ }^{73,74}$ and small molecules. ${ }^{47}$ However, there are few types of functional monomers and limited combinations. Two main considerations need to be made, namely, smartly designing and synthesizing new functional monomers and properly selecting and rationally combining different functional monomers that are available. Furthermore, the optimal synergistic efficiency will be utilized to create ideal MIPs and thereby MIP-SERS sensors related research will achieve a huge leap.

Dummy Template Imprinting for Improving Accuracy and Expanding to More Analytes. Template leakage/ residue is an important factor affecting the performances of MIP-SERS sensors and directly results in low quantitative accuracy and high background interference. ${ }^{75}$ To solve this problem, the structural analogue of the targeted analyte instead of the actual analyte is selected as the template molecule in the imprinting procedure, ${ }^{76}$ which is called dummy template imprinting, as illustrated in Figure $3 \mathrm{~B}$. The key to effectively using this strategy is to find a dummy template that is similar to the analytes in size, shape, and functional groups. And the molecule does not have a Raman signal or have a Raman signal different from the analyte's characteristic peak. As a structural analogue of crystal violet $(\mathrm{CV})$, rosin acid does not have the SERS signal and is used to construct a dummy MIP based SERS sensor (Ag@DMIP) as a dummy template molecule. ${ }^{77}$ In this sensor, the ionic interaction between $\mathrm{CV}$ and carboxylic group residues of abietic acid is the main rebinding force, which ensures the high selectivity of Ag@DMIP. ${ }^{77}$

More importantly, dummy template imprinting plays a crucial role when the original analyte is not suitable as a template, owing to its high cost, toxicity, unavailability, or instability as well as the disturbance in the polymerization process. $^{78}$ Carboni et al. ${ }^{72}$ have used diethyl (4-nitrobenzyl)phosphonate which is the unhydrolyzable structural analog of the commercial pesticide p-oxophosphorus as a template 


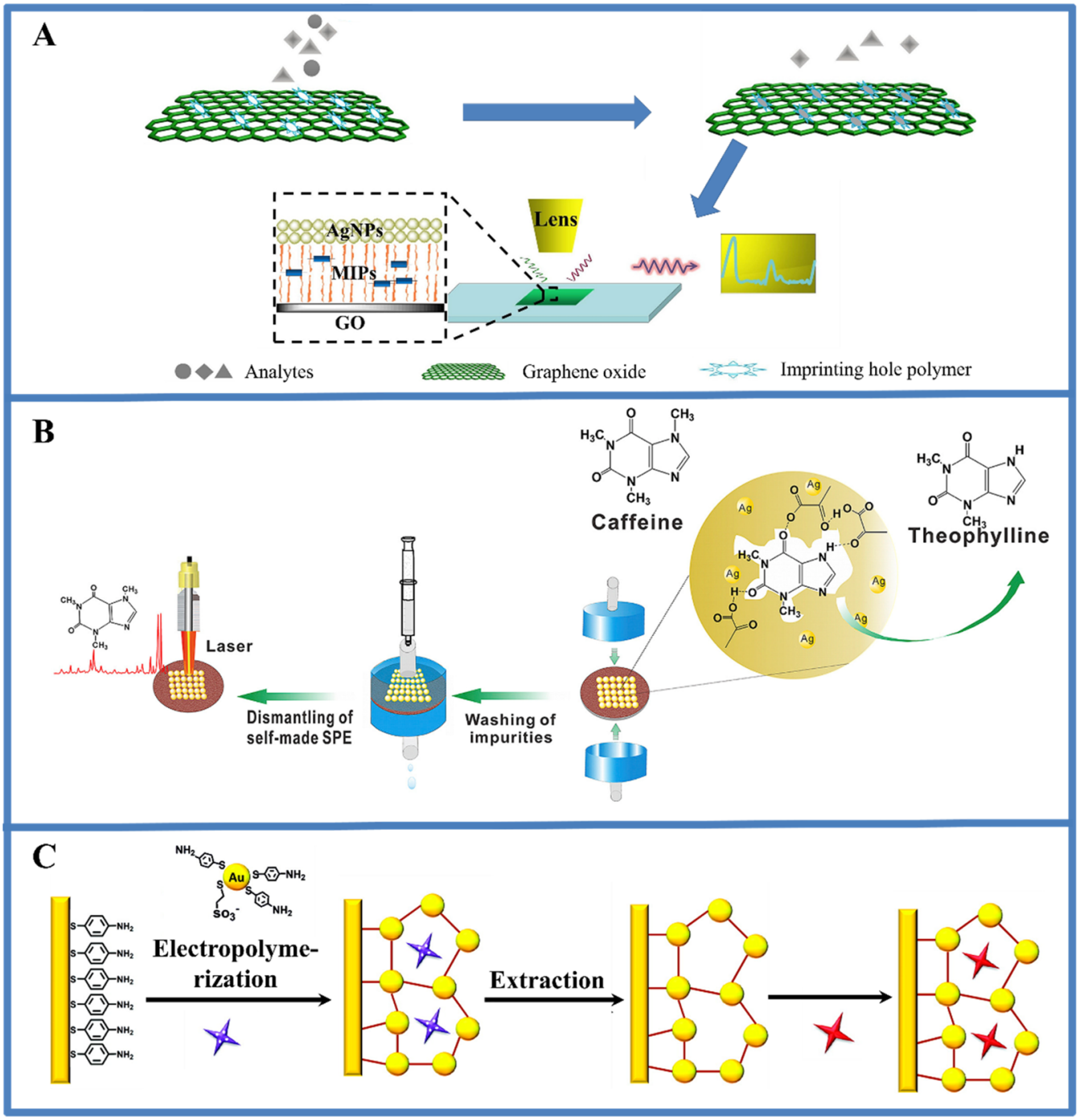

Figure 6. (A) Schematic illustration of the construction process and detection mechanism for GO@MIPs-PRO@ Ag NPs sensor. Adapted with permission from ref 90. Copyright 2018 Elsevier Science SA. (B) Schematic illustration of a MIP packed SPE procedure for detecting caffeine by Raman spectroscopy. Reprinted with permission from ref 45. Copyright 2018 Elsevier Science BV. (C) Schematic illustration of MIP-SERS sensor construction for the detection of NG and PETN using citric acid as the template. Adapted with permission from ref 68. Copyright 2011 American Chemical Society.

molecule to construct a MIP-SERS sensor. The sensor based on the dummy template technique has good capture selectivity of MIPs' spatial recognition and fingerprint spectral selectivity of Raman. The combined effect of these two types of selectivity greatly enhances the selectivity of MIP-SERS sensor, which cannot be achieved by using MIPs and SERS separately. ${ }^{72}$

As mentioned above, the dummy template imprinting strategy not only solves the template leakage problem and improves detection accuracy, but also overcomes specialtargets imprinting obstacle and expands MIP-SERS to more analytes. However, it is still quite difficult to select the dummy templates. For example, at this stage, this technique can hardly be adopted to construct MIP-SERS sensors for proteins analysis. Because proteins have bulk and twist structures as well as unclear position and sequence of functional groups, it is almost impossible to choose appropriate structural analogs based on related parameters such as morphology and functional groups.

Living/Controlled Radical Polymerization for Increasing Sensitivity. In general, MIP thickness should be controlled to achieve high adsorption capacity and SERS activity. ${ }^{71,79}$ Although the MIP layer thickness can be dominated by controlling the amount of cross-linker/silanating agents in the polymerizations, this method is cumbersome and difficult to perceive. ${ }^{80}$ Living/controlled radical polymerization (LCRP), mainly including atom transfer radical polymerization (ATRP) and reversible addition-fragmentation chain transfer (RAFT), is effective for easily and accurately controlling the thickness of MIPs by controlling the chain transfer and chain termination reactions in the polymerization process, ${ }^{39}$ as shown in Figure 3C.

$\mathrm{Li}$ et al. ${ }^{47}$ synthesized $\mathrm{SiO}_{2} @ \mathrm{rGO} @ A g-\mathrm{MIP}$ by ATRP method to control the thickness of the MIPs layer. When the dopamine self-polymerization and ATRP reaction time were 8 and 12 h, respectively, the $\mathrm{SiO}_{2} @ \mathrm{rGO} @ \mathrm{Ag}$-MIP sensor attained the highest Raman signal and thereby high detection sensitivity. Unfortunately, the application of the ATRP method is limited, since it is incompatible with some common functional monomers such as methacrylic acid and vinylpyridine. $^{81}$ Compared with the ATRP method, the RAFT 
Table 2. Applications of MIP-SERS Sensors for Chemical and Biological Analysis

\begin{tabular}{|c|c|c|c|c|c|c|c|c|}
\hline analyte & $\begin{array}{c}\text { SERS } \\
\text { substrates }\end{array}$ & structure & $\begin{array}{l}\text { novel imprinting } \\
\text { technique }\end{array}$ & polymerization method & sample & $\mathrm{LOD}(\mathrm{mol} / \mathrm{L})$ & $\mathrm{EF}^{a}$ & refs \\
\hline PRO & Ag NPs & S-o-M & & $\begin{array}{l}\text { precipitation } \\
\text { polymerization }\end{array}$ & & $1 \times 10^{-11}$ & $3.95 \times 10^{7}$ & 90 \\
\hline BPA & Ag NPs & M-o-S & & sol-gel & & $1.46 \times 10^{-11}$ & $1.2 \times 10^{5}$ & 46 \\
\hline BSA & Ag NPs & M-o-S & $\begin{array}{l}\text { multifunctional } \\
\text { monomer }\end{array}$ & sol-gel & & $1 \times 10^{-8}$ & $5.56 \times 10^{5}$ & 74 \\
\hline$\lambda$-cyhalothrin & $\begin{array}{l}\mathrm{SiO}_{2} @ \mathrm{rG}- \\
\mathrm{O} @ \mathrm{Ag}\end{array}$ & M-o-S & $\begin{array}{l}\text { living/controlled radical } \\
\text { polymerization }\end{array}$ & $\begin{array}{l}\text { living/controlled radical } \\
\text { polymerization }\end{array}$ & water & $3.8 \times 10^{-10}$ & $6.4 \times 10^{6}$ & 47 \\
\hline 2,6-dichlorophenol & Ag@CdTe & M-o-S & $\begin{array}{l}\text { living/controlled radical } \\
\text { polymerization }\end{array}$ & $\begin{array}{l}\text { living/controlled radical } \\
\text { polymerization }\end{array}$ & water & $1 \times 10^{-9}$ & $1.33 \times 10^{6}$ & 121 \\
\hline chloramphenicol & Au NPs & S-o-M & & $\begin{array}{l}\text { precipitation } \\
\text { polymerization }\end{array}$ & milk & $1 \times 10^{-7 b}$ & $9 \times 10^{3}$ & 158 \\
\hline R6G & $\mathrm{SiO}_{2} @ \mathrm{Ag}$ & M-o-S & & $\begin{array}{l}\text { precipitation } \\
\text { polymerization }\end{array}$ & water & $1 \times 10^{-12}$ & $3 \times 10^{6}$ & 51 \\
\hline enrofloxacin & $\begin{array}{l}\mathrm{bAu} @ \mathrm{~m}- \\
\mathrm{SiO}_{2}\end{array}$ & M-o-S & $\begin{array}{l}\text { living/controlled radical } \\
\text { polymerization }\end{array}$ & $\begin{array}{l}\text { living/controlled radical } \\
\text { polymerization }\end{array}$ & & $1.5 \times 10^{-9}$ & & 39 \\
\hline transferrin & $\begin{array}{l}\text { gold } \\
\text { nanorods }\end{array}$ & M-o-S & & $\begin{array}{l}\text { dopamine self- } \\
\text { polymerization }\end{array}$ & blood & $1 \times 10^{-8}$ & & 20 \\
\hline horseradish peroxidase & Ag NPs & $M-m-S$ & & bulk polymerization & serum & $1 \times 10^{-10}$ & & 66 \\
\hline 4-mercaptobenzoic acid & Ag NPs & M-o-S & & $\begin{array}{l}\text { precipitation } \\
\text { polymerization }\end{array}$ & & $1 \times 10^{-15}$ & & 159 \\
\hline TNT & Klarite & M-o-S & $\begin{array}{l}\text { multifunctional } \\
\text { monomer }\end{array}$ & sol-gel & & $3 \times 10^{-6}$ & & 80 \\
\hline theophylline & Ag NPs & $M-m-S$ & & bulk polymerization & & $1 \times 10^{-6}$ & & 62 \\
\hline PETN & Au NPs & S-o-M & dummy template & electropolymerization & & $2 \times 10^{-10}$ & & 68 \\
\hline NG & Au NPs & S-o-M & dummy template & electropolymerization & & $2 \times 10^{-8}$ & & 68 \\
\hline ethylene glycol dinitrate & Au NPs & S-o-M & dummy template & electropolymerization & & $4 \times 10^{-10}$ & & 68 \\
\hline ethylene glycol dinitrate & $\mathrm{Au}$ NPs & S-o-M & dummy template & electropolymerization & & $4 \times 10^{-10}$ & & 68 \\
\hline TNT & Ag NPs & S-o-M & & $\begin{array}{l}\text { photocatalytic } \\
\text { polymerization }\end{array}$ & & $1 \times 10^{-12}$ & & 94 \\
\hline$(S)$-PRO & Klarite & M-o-S & & $\begin{array}{l}\text { photocatalytic } \\
\text { polymerization }\end{array}$ & & & & 64 \\
\hline$(S)$-PRO & AET@Au & M-o-S & & emulsion polymerization & & $1 \times 10^{-7}$ & & 49 \\
\hline$(S)$-PRO & Klarite & M-o-S & & $\begin{array}{l}\text { photocatalytic } \\
\text { polymerization }\end{array}$ & urine & & & 65 \\
\hline $\begin{array}{l}(2 S, 3 S)-(+)-\mathrm{di}-O- \\
\text { benzoyltartaric acid }\end{array}$ & $\begin{array}{l}\text { noble } \\
\text { metals }\end{array}$ & M-o-S & & $\begin{array}{l}\text { photocatalytic } \\
\text { polymerization }\end{array}$ & water & & & 36 \\
\hline $\begin{array}{l}N \text {-benzyloxycarbonyl- } \\
(L) \text {-aspartic acid }\end{array}$ & $\begin{array}{l}\text { noble } \\
\text { metals }\end{array}$ & M-o-S & & $\begin{array}{l}\text { photocatalytic } \\
\text { polymerization }\end{array}$ & water & & & 36 \\
\hline BPA & $\mathrm{Au}$ NPs & M-o-S & & sol-gel & & $5.3 \times 10^{-7}$ & & 141 \\
\hline R6G & $\mathrm{ZnO} / \mathrm{Ag}$ & M-o-S & stimuli-responsive & $\begin{array}{l}\text { precipitation } \\
\text { polymerization }\end{array}$ & water & $1 \times 10^{-13}$ & $1 \times 10^{7}$ & 83 \\
\hline ALP & $\begin{array}{l}\text { metal@- } \\
\text { gold }\end{array}$ & M-m-S & & & biological & $6 \times 10^{-11 b}$ & $1.8 \times 10^{9 b}$ & 104 \\
\hline survivin & $\begin{array}{l}\text { metal@- } \\
\text { gold }\end{array}$ & $M-m-S$ & & & biological & $3 \times 10^{-13 b}$ & $2.5 \times 10^{9 b}$ & 104 \\
\hline erythropoietin & $\mathrm{SiO}_{2} @ \mathrm{Au}$ & $M-m-S$ & & & urine & $2.9 \times 10^{-14}$ & & 67 \\
\hline ALP & $\mathrm{SiO}_{2} @ \mathrm{Au}$ & M-m-S & & sol-gel & biological & $3.1 \times 10^{-12}$ & & 105 \\
\hline $\mathrm{AFP}$ & $\mathrm{SiO}_{2} @ \mathrm{Au}$ & M-m-S & & sol-gel & biological & $1.5 \times 10^{-14}$ & & 105 \\
\hline R6G & Ag NPs & M-o-S & & $\begin{array}{l}\text { precipitation } \\
\text { polymerization }\end{array}$ & & $1 \times 10^{-14}$ & $1 \times 10^{8}$ & 160 \\
\hline Sudan IV & $\mathrm{Au}$ NPs & $M-m-S$ & & $\begin{array}{l}\text { precipitation } \\
\text { polymerization }\end{array}$ & & & & 50 \\
\hline BPA & Ag NPs & M-o-S & & $\begin{array}{l}\text { precipitation } \\
\text { polymerization }\end{array}$ & tap water & $1 \times 10^{-9}$ & & 161 \\
\hline BPA & $\mathrm{Ag}$ NPs & M-m-S & & bulk polymerization & & $5 \times 10^{-8}$ & $1 \times 10^{6}$ & 44 \\
\hline caffeine & Ag NPs & M-m-S & dummy template & $\begin{array}{l}\text { precipitation } \\
\text { polymerization }\end{array}$ & $\begin{array}{l}\text { waste } \\
\text { water }\end{array}$ & $4.7 \times 10^{-10 b}$ & & 45 \\
\hline cyhalothrin & Ag NPs & M-o-S & & $\begin{array}{l}\text { precipitation } \\
\text { polymerization }\end{array}$ & river & $1.3 \times 10^{-5}$ & $1.73 \times 10^{5}$ & 38 \\
\hline glucose & $\begin{array}{l}\text { metal@- } \\
\text { gold }\end{array}$ & M-m-S & & sol-gel & fruit & $5.6 \times 10^{-12}$ & & 152 \\
\hline fructose & $\begin{array}{l}\text { metal@- } \\
\text { gold }\end{array}$ & M-m-S & & sol-gel & fruit & $5.6 \times 10^{-9}$ & & 152 \\
\hline rhodamine B & Ag NPs & M-o-S & & $\begin{array}{l}\text { precipitation } \\
\text { polymerization }\end{array}$ & water & $1 \times 10^{-12}$ & $1.01 \times 10^{7}$ & 41 \\
\hline rhodamine $\mathrm{B}$ & Ag NPs & M-o-S & & $\begin{array}{l}\text { precipitation } \\
\text { polymerization }\end{array}$ & & $1 \times 10^{-10}$ & $1.6 \times 10^{5}$ & 21 \\
\hline
\end{tabular}


Table 2. continued

\begin{tabular}{|c|c|c|c|c|c|c|c|c|}
\hline analyte & $\begin{array}{c}\text { SERS } \\
\text { substrates }\end{array}$ & structure & $\begin{array}{l}\text { novel imprinting } \\
\text { technique }\end{array}$ & polymerization method & sample & $\mathrm{LOD}(\mathrm{mol} / \mathrm{L})$ & $\mathrm{EF}^{a}$ & refs \\
\hline PRO & Klarite & M-o-S & & $\begin{array}{l}\text { precipitation } \\
\text { polymerization }\end{array}$ & & $3 \times 10^{-6}$ & & 63 \\
\hline
\end{tabular}

method can react with common monomers under mild reaction conditions, is suitable for free radical polymerization, and has a wider application space. ${ }^{81}$ Carrasco et al. ${ }^{39}$ prepared a "star" multibranched gold-silica-MIP (bAu@mSiO $2 @ M I P)$ core-shell NPs (Figure 5A). The surface of $\mathrm{SiO}_{2}$ was functionalized with the RAFT reagent, and then the MIPs were controllably synthesized on it. Compared to other MIPSERS sensors, this sensor offers a 2 orders of magnitude lower limit of detection (LOD) for enrofloxacin, which is one of the lowest reported values.

The above discussion shows that the detection sensitivity of MIP-SERS sensors can be markedly increased by applying the LCRP method, while the LCRP reagent needs to be fixed on the surface of the substrate, resulting in complicated operations and lower success rates. Thus, if new SERS substrates or grafting methods can be found to adequately achieve grafting of LCRP reagents onto SERS substrates, the tight integration of SERS substrates and MIPs can be further optimized, contributing to fabricating more and excellent MIP-SERS sensors.

Stimuli-Responsive Imprinting for Intelligent Detection. The stimuli-responsive imprinting technique is to achieve intelligently controllable recognition by using a responsive monomer or magnetic core under external physicochemical or biological stimuli, ${ }^{82}$ as shown in Figure 3D. Accordingly, the stimuli-responsive MIP-SERS (SR-MIP-SERS) sensor can not only alleviate template leakage and elution difficulties, but also reduce material loss and time consumption in the separation process. The crux to effectively use this technique is to find stimuli-responsive functional monomers with responsive groups.

In the development of MIP-SERS sensors, the thermoresponsive technique based on the thermosensitive monomer of $\mathrm{N}$-isopropylacrylamide (NIPAAm) has been successfully utilized. ${ }^{83}$ Since the size of the polymer prepared by the NIPAAm can change with ambient temperature, the controllable binding and release of the analytes can be realized by adjusting the temperature of the ambient. As seen from Figure $5 \mathrm{~B}$, when the temperature is $30{ }^{\circ} \mathrm{C}$, the shape of the molecularly imprinted cavity can completely match the shape of the template. Under the optimal conditions, the binding capacity of thermoresponsive $\mathrm{ZnO} / \mathrm{Ag} / \mathrm{MIP}$ (ZOA-TMIP) to rhodamine $6 \mathrm{G}(\mathrm{R} 6 \mathrm{G})$ is the highest. ${ }^{83}$ Moreover, the magnetic responsive MIP-SERS sensor (M-MIP-SERS sensor) with $\mathrm{Fe}_{3} \mathrm{O}_{4} @ \mathrm{SiO}_{2} @ \mathrm{Ag}$ as the SERS substrate has also been successfully used for the detection of sibutramine in pharmaceuticals. ${ }^{84}$ M-MIP-SERS sensors can not only perform controlled rebinding, but also conveniently and economically replace the centrifugation and filtration steps by simple effective magnetic separation. ${ }^{82,84,85}$ Therefore, extraction and purification can be finished in one step, which is very beneficial for quantitative detection in the presence of matrix interferences. $^{86}$

Although the stimuli-responsive imprinting strategy makes an influential contribution to intelligent detection, limited types of SR-MIP-SERS sensors have been reported with only thermoresponsive and magnetic responsive ones available. Therefore, it is in high demand to construct new types of SRMIP-SERS sensors, such as $\mathrm{pH}$-responsive, photoresponsive, and multiresponsive ones, and apply them in drug delivery, life science, and other fields. This requires synthesizing various stimuli-responsive monomers to meet construction needs.

\section{APPLICATIONS OF MIP-SERS SENSORS FOR CHEMO- AND BIOANALYSIS}

A variety of as-constructed MIP-SERS sensors that are attractive and strongly competitive have found a wide range of applications for chemo- and bioanalysis. Their representative applications for the detection of small molecules and macromolecules are summarized as follows.

Small Molecule Detection. MIP-SERS sensors realize selective, sensitive, and simple detection for many types of small molecules in complex biological and environmental matrices, mainly including drugs, pesticides, organic pollutants, and illicit substances.

These residues from drugs, pesticides, and organic pollutants pose severe threats to the environment and organisms, and they are usually present at (ultra)trace levels in complicated matrices, which are hard to detect. ${ }^{87-89}$ MIP-SERS sensors have shown great potential to solve this problem. For example, a MIP-SERS sensor based on graphene oxide (GO), MIPs, and AgNPs has been fabricated for propranolol (PRO) detection (Figure 6A). ${ }^{90} \mathrm{GO}$, as a supporting substrate, enhances the accessibility and sensitivity of the analyte ${ }^{91,92}$ due to its high specific surface area and the chemical enhancement of the Raman scattering effect. ${ }^{93}$ Similarly, reduced GO (rGO) has also been successfully used to prepare SiO $2 @ \mathrm{rGO} @ \mathrm{Ag} @ \mathrm{MIPs}$ for $\lambda$-cyhalothrin detection. ${ }^{47}$ In addition, an attempt was made to combine solid phase extraction (SPE) with the MIP-SERS sensors to detect caffeine from the complex wastewater (Figure $6 \mathrm{~B})$, avoiding analyte loss in the elution and concentration process. $^{45}$ Compared with traditional SPE columns, the columns packed with AgNPs@MIPs realized the direct and fast detection of caffeine by SERS within $23 \mathrm{~min}$.

The efficient detection of illicit substances with high selectivity and sensitivity plays a critical role in antiterrorism and homeland security. ${ }^{94}$ In 2010, Yang and co-workers ${ }^{94}$ developed the first MIP-SERS sensor to detect 2,4,6trinitrotoluene (TNT), which is composed of silver molybdate nanowires (SMNs), $p$-aminothiophenol-functionalized AgNPs, the template molecule TNT, and the cross-linker $p, p^{\prime}$ dimercaptoazobenzene. The main advantage of this sensor is that SMN generates new AgNPs to cover the surface of AgSMN-MIPs under laser irradiation during the SERS measurement, thus effectively enhancing the sensitivity. Moreover, in order to simultaneously identify, separate and measure different substances in the same category, Riskin and coworkers $^{68}$ developed a MIP-SERS sensor using citric acid with the carboxylic acid functional group as template and realized the concurrent determination of nitroglycerin (NG) and pentaerythritol tetranitrate (PETN) (Figure 6C), greatly expanding the applications of MIP-SERS sensors in practice. 


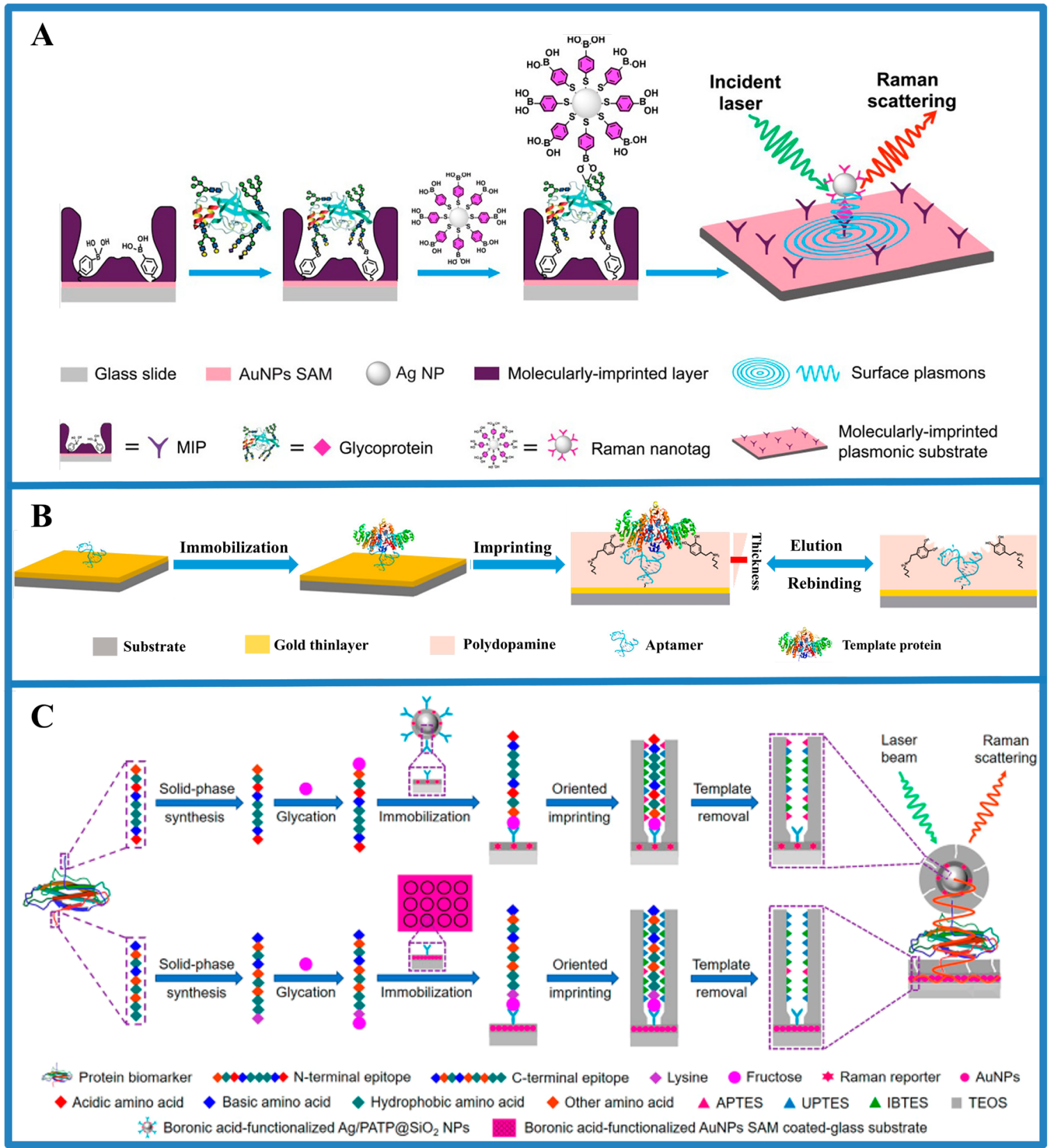

Figure 7. (A) Schematic illustration of the MIP-based PISA approach for SERS detection of target glycoproteins. Reprinted with permission from ref 105. Copyright 2017 American Chemical Society. (B) Schematic illustration of the procedure for preparing aptamer-MIP hybrid SERS sensor. Adapted with permission from ref 108. Copyright 2019 American Chemical Society. (C) Schematic illustration of the MIP-protein-MIP sandwich-like complexes for SERS detection of neuron-specific enolase. Reprinted with permission from ref 73 . Copyright 2019 American Chemical Society.

So far, MIP-SERS sensors have shown advantages in the detection of many kinds of small molecules by recording SERS signals of the analytes themselves, ${ }^{95}$ as listed in Table 2 . The combination with other technologies such as microfluidics ${ }^{55,96,97}$ will improve the reproducibility of MIP-SERS sensors, which is an important direction deserved to be explored.

Macromolecule Detection. Macromolecules such as $\alpha$ fetoprotein (AFP), carcinoembryonic antigen (CEA), and alkaline phosphatase (ALP $)^{98-101}$ have been widely used as biomarkers in clinical diagnosis. The concentration of the biomarkers is usually very low (in the range of $10^{-16}-10^{-12}$ $\mathrm{M})$, but the interfering substances are very complicated, leading to a huge difficulty in the accurate determination. ${ }^{102}$ Enzyme-linked immunosorbent assays (ELISAs) are popular but they are expensive and time-consuming. ${ }^{74}$ The MIP-SERS sensors provide an alternative way which is effective and more simple and economic. ${ }^{103}$ For example, a MIP-SERS sensor has been used for the rapid qualitative and quantitative detection of bovine serum albumin (BSA) using hydrogel as the imprinting layer with particularly good hydrophilicity and selectivity. $^{74}$

To further increase the target-capturing specificity, some conventional recognition ligands have also been introduced into MIP synthesis. Recently, Liu and co-workers have developed the boronate-affinity sandwich assay (BASA) ${ }^{66}$ 

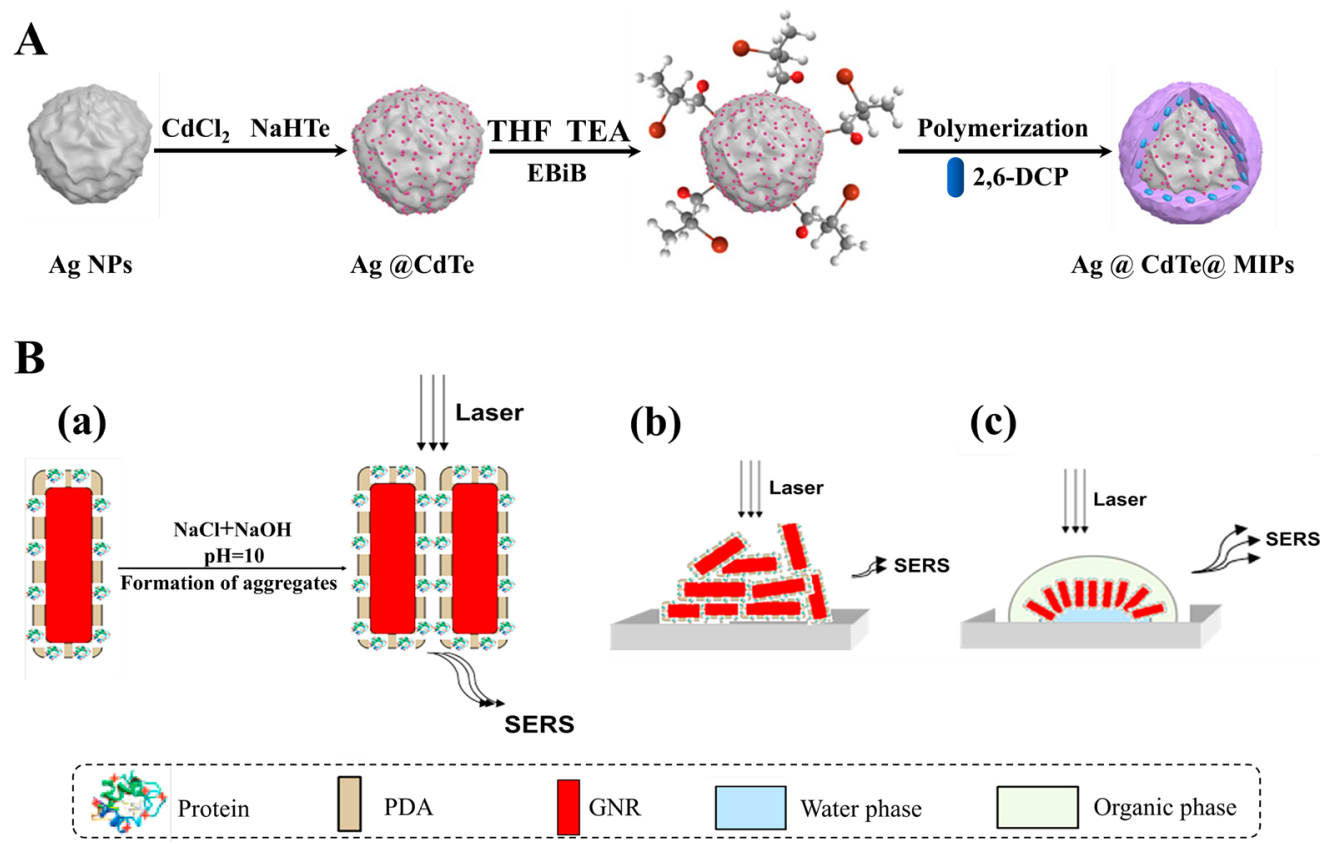

Figure 8. (A) Schematic illustration for the preparation of Ag@CdTe@MIPs and the SERS detection of 2,6-dichlorophenol upon specific recognition. Adapted with permission from ref 121. Copyright 2018 Wiley. (B) Schematic illustration of using different approaches for SERS measurements: (a) aggregation of bioconjugates, (b) stacking of bioconjugates on glass plate, and (c) self-assembly of bioconjugates forming closepacked arrays. Adapted with permission from ref 20. Copyright 2016 Elsevier Advanced Technology.

and the upgraded version termed plasmonic immuno-sandwich

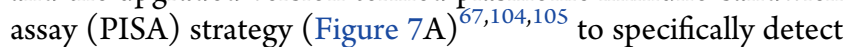
trace glycoproteins in complex samples based on reversible binding between boric acid and cis-diol-containing biomolecules through covalent bonds. ${ }^{106}$ In particular, PISA can achieve ultrasensitive detection at the single molecule level by the additional amplification mechanism of the noble metals in the capture substrates. ${ }^{104}$ The orientation of macromolecules greatly affects the Raman signals; that is, vibrational modes perpendicular to the surface of the SERS substrates can be amplified by the local electromagnetic field, while those parallel ones show weak or even undetectable intensities. ${ }^{107}$ To avoid the analyte-orientation induced Raman spectroscopy fluctuation, the combination between aptamer and boronate-affinity MIPs is proposed to construct a sensor for ALP detection. As shown in Figure $7 \mathrm{~B}$, the self-polymerization of dopamine controls the orientation of the aptamer-MIP hybrids. This hybrid significantly improves the specificity and affinity for ALP with the IF up to 9.5 and the LOD an order of magnitude lower than that of aptamer-prepared MIPs. ${ }^{108}$

The above-mentioned MIP-SERS sensors mainly use the entire protein molecule as template. However, since proteins are easily deformed in harsh conditions and not easily to eluted from the cross-linked polymer network, protein imprinting is still a huge challenge. ${ }^{109}$ In 2000, using epitopes as templates to prepare MIPs was first proposed by Minoura and Rachkov, ${ }^{110,111}$ which can effectively resolve the main problems of protein imprinting. Since then, epitope imprinting has been widely used in protein imprinting. Recently, Liu and co-workers ${ }^{73}$ have developed a controllable oriented surface dual MIP based plasmonic immunosandwich assay (duMIPPISA) for protein detection. C-Terminal epitope peptides and $\mathrm{N}$-terminal epitope peptide fragments fixed on the boronic acid-functionalized substrates through glycosylation reaction are polycondensed with the four silylating reagents, which greatly alleviates the problem of low imprinting efficiency caused by the epitopes buried in the polymer (Figure $7 \mathrm{C}$ ). ${ }^{73}$ Besides, the dual recognition of the prepared MIP-proteinMIP sandwich-like complexes ensures high specificity for neuron-specific enolase (NSE) detection, while SERS detection offers ultrahigh sensitivity. Therefore, the duMIPPISA has been applied to serum samples from healthy individuals and small cell lung cancer patients, providing a new way for protein identification. Compared with the commonly commercial ELISA for detecting NSE, the MIPSERS method has the remarkable advantages of short time, simple operation, wider linear range, and smaller sample usage. $^{73}$ Therefore, MIP-SERS sensors act as an irreplaceable role in many important applications such as disease diagnosis.

\section{CHALLENGES AND PERSPECTIVES}

Recent years have witnessed the flourishing development and wide applications of MIP-SERS sensors. Still, some challenges need to be addressed, and accordingly promising perspectives can be proposed, mainly including three aspects: improving the sensitivity, enhancing the reproducibility, and expanding the application of MIP-SERS sensors.

Improving the Sensitivity of MIP-SERS Sensors. Sensitivity is a key parameter to evaluate the performance of MIP-SERS sensors, which is mainly dependent on the enhancement ability of the SERS substrates. Researchers have endeavored to improve the sensitivity of MIP-SERS sensors in two directions, i.e., preparing novel types of SERS substrates and using controllable aggregation detection modes.

Preparation of Novel SERS Substrates. Some studies have suggested that when the metal NPs are combined with the metal-semiconductor heterojunction, the SERS signals will be significantly enhanced. ${ }^{112-114}$ Consequently, a significant enhancement at neck interconnections between associated NPs or in metal-semiconductor heterostructures contributes 
$\mathbf{A}$

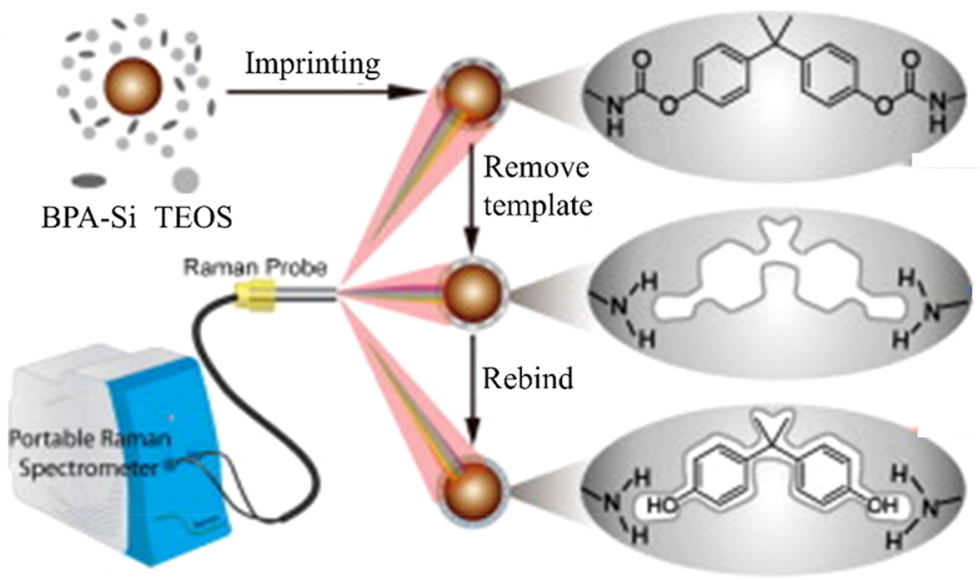

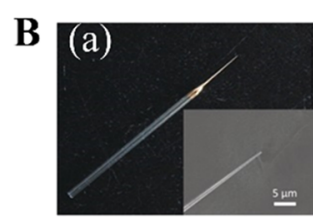

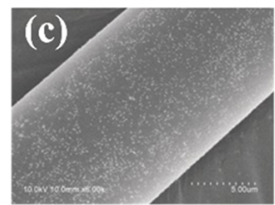

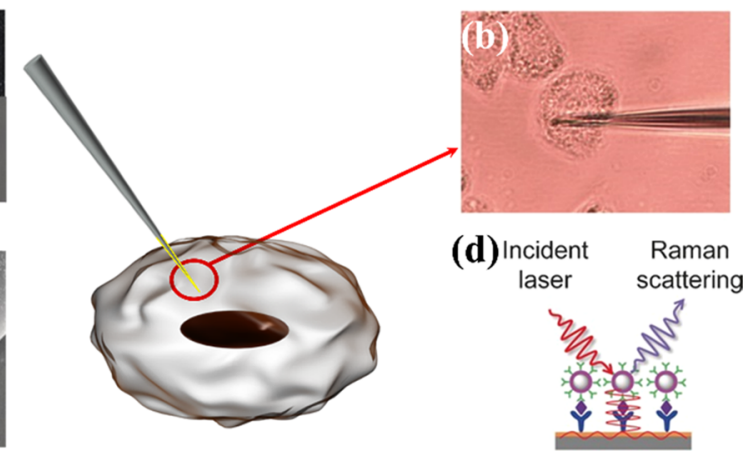

Figure 9. (A) Schematic illustration for fabricating MIP-ir-AuNPs by a sol-gel method and using MIP-ir-AuNPs for selective detection of BPA using a small portable Raman spectrometer. Reprinted with permission from ref 141. Copyright 2013 Elsevier Science BV. (B) Schematic illustration for extraction microprobe inserted into a single cell: (a) photo and SEM images of an extraction microprobe, (b) image showing an extraction microprobe inserted into a single cell, (c) SEM image showing immune-sandwiches formed on an extraction microprobe after extracting target protein from a single cell and being labeled with Raman nanotags, and (d) schematic diagram of Raman nanotags combined with an extraction microprobe. Adapted with permission from ref 104. Copyright 2016 Wiley-VCH Verlag GmbH.

specific metal-semiconductor interface interactions and signal intensification. ${ }^{115,116}$ Therefore, the SERS effect of the metal NPs can be further promoted based on the electromagnetic enhancement by combining the metal NPs with the metalsemiconductor heterojunction. ${ }^{117-120}$ Common metal-semiconductor heterojunction structures mainly include CdTe quantum dots (QDs), ${ }^{121,122} \mathrm{TiO}_{2}{ }^{112,113}$ and $\mathrm{ZnO} .{ }^{116} \mathrm{Li}$ and co-workers $^{121}$ used CdTe QD-loaded AgNPs as the core to construct a new MIP-SERS sensor (Figure 8A). The sensor had good sensitivity, stability, and selectivity. After that, the same group combined the SERS substrates of a metal NPmetal-semiconductor heterojunction structure with MIPs to develop a $\mathrm{ZnO} / \mathrm{Ag}$ MIP-SERS sensor (ZOA-MIPs) for the specific detection of R6G in water for the first time. When using MIP-SERS sensors, $\mathrm{ZnO} / \mathrm{Ag}$ heterostructures, and AgNPs detection, the LODs of R6G were $1 \times 10^{-12}, 1 \times$ $10^{-7}$, and $1 \times 10^{-6}$, respectively. The results revealed that the prepared sensor can selectively bind and significantly enhance the Raman signal of R6G. Besides, the ZOA-MIPs possessed self-cleaning ability under ultraviolet light due to the excellent degradation ability of the $\mathrm{ZnO} / \mathrm{Ag}$, leading to recyclability. ${ }^{123}$ Therefore, this technology can greatly improve the sensitivity of the MIP-SERS sensors and broaden their application fields. ${ }^{40,124}$

Additionally, with the extension of the SERS field, composite metal NPs composed of two or more elements owning unique properties have attracted great research interest. Based on this, researchers have further proposed the nanosubstrate of SERS probes with bimetallic core-shell NPs and bimetallic alloy NPs, mainly including $\mathrm{Au} @ \mathrm{Ag} \mathrm{NPs}^{95,125-128}$ with $\mathrm{Au}$ as the core, Ag@Au NPs ${ }^{129-132}$ with Ag as the core, and $\mathrm{Au}-\mathrm{Ag}$ alloy NPs. ${ }^{133-136}$ Relying on these technologies, more and new MIP-SERS sensors with composite metal NPs as SERS substrates can be further developed, thereby achieving further improvement in sensitivity.

Developing Controllable-Aggregation Detection Mode. The controllable aggregation of the MIP-SERS sensors is an effective way to increase the sensitivity of the sensors. ${ }^{43} \mathrm{Lv}$ et al. $^{20}$ synthesized MIPs@gold nanorod (GNR) composites by using GNR as the reinforcing substrate, transferrin as the template molecule, and dopamine as the functional monomer (Figure 8B). SERS measurement was performed by using three different methods: (1) formation of protein imprinted GNR aggregates, (2) stacking of the protein imprinted GNRs on a glass plate, and (3) self-assembly of protein imprinted GNRs into close-packed arrays. The results showed that the nanoaggregates had the highest degree of Raman enhancement. This strategy deserves further study to precisely control the formation of nanoaggregates and clarify the signalaggregation state relationship.

Enhancing the Reproducibility of MIP-SERS Sensors. Reproducibility is another important factor to determine the practical application performance of MIP-SERS sensors, which is closely related to the reproducibility of the SERS 


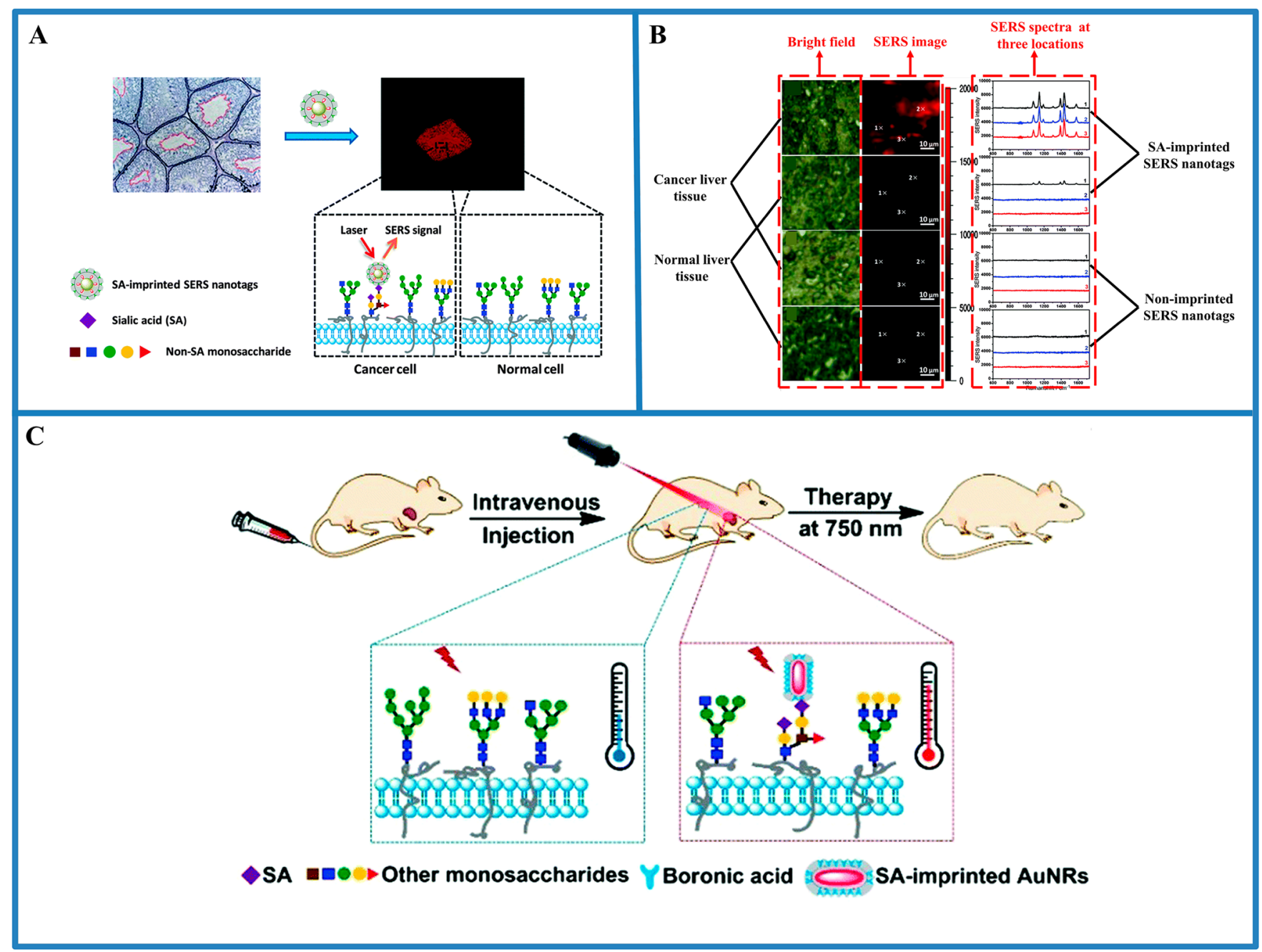

Figure 10. (A) Schematic for SERS imaging of cancer cells and tissues via SA-imprinted MIP-SERS sensors. Reprinted with permission from ref 154. Copyright 2015 Royal Society of Chemistry. (B) SERS imaging of cancer and normal liver tissues. Adapted with permission from ref 154. Copyright 2015 Royal Society of Chemistry. (C) Illustration of the principle for targeted photothermal therapy via SA-imprinted AuNRs@SiO 2. Reprinted with permission from ref 157. Copyright 2017 Royal Society of Chemistry.

substrates. $^{82}$ To date, the researchers have proposed two methods to improve the SERS detection reproducibility, namely, by introducing internal standard (IS) and by preparing highly uniform SERS substrates.

For example, core-shell nanosubstrates with embedded IS reporters (4-mercaptopyridine) have been devised for reliable quantitative SERS analysis. The introduction of IS signal can calibrate the fluctuation of analyte (1,4-phenylene diisocyanide) signals caused by changes of particle aggregation state and measurement conditions. ${ }^{137}$ Ashley et al. ${ }^{82}$ have used acetic acid as an IS to achieve quantitative detection of clozacillin in pig serum. Relative standard deviations (RSDs) are in a range of $3.9-18.7 \%$. The result proves that the method has good reproducibility. Another route is to prepare highly uniform SERS substrates from the aspect of optimizing microstructures, which have high-density array of noble metal NPs on solid supports by block copolymer NP selfassembly. Cho et al. ${ }^{138}$ have fabricated a highly uniform array of silver nanoclusters on a silicon wafer based on the reduction of $\mathrm{AgNO}_{3}$ in polystyrene-blockpoly(4-vinylpyridine) copolymer (PS- $b$-P4VP) micelles, followed by spin-coating and UV irradiation. The result of measured Raman intensity was quite reproducible, less than $5 \%$ over 30 experimental runs. Besides, some physical techniques such as lithography have also been applied to prepare highly uniform SERS substrates. Large-area ordered hexagonal-packed SiNR@AuNP SERS substrates have been successfully prepared by metal-assisted chemical etching and lithography. ${ }^{139}$ The substrate has controllable gaps and uniformly covered $\mathrm{Au}$ NPs with high sensitivity and reproducibility (RSDs $=3.9-7.2 \%$ ). In addition, highresolution electron-beam lithography has been employed to prepare monodisperse gold nanoblocks with high reproducibility on glass substrates. ${ }^{140}$ Nowadays, the IS method ${ }^{82}$ and lithography ${ }^{64,66}$ have been introduced into the construction of MIP-SERS sensors, but there is still a long way to go to solve the problem of reproducibility of MIP-SERS sensors.

Expanding the Application of MIP-SERS Sensors. To date, research on MIP-SERS sensors is mainly at the stage of structural design and proof-of-concept detection in the lab, whereas practical applications are rarely mentioned. With the development and maturity of MIP-SERS sensors, application research should be put on the agenda. Considering the advantages of MIP-SERS sensors, such as miniaturization, rapidity, high selectivity, and sensitivity, successful applications in many fields can be expected including in situ rapid detection and biological detection in the microscopic scale. 
In Situ Rapid Detection. It is an essential and urgent requirement to carry out in situ rapid detection in many fields such as environmental monitoring and food safety analysis. MIP-SERS sensors combined with portable Raman instruments can play an important role in this area. For instance, Xue et al. ${ }^{141}$ prepared a MIP-ir-AuNPs sensor in conjunction with the small portable Raman spectrometer (Figure 9A), accomplishing the real-time detection of bisphenol A (BPA). Cao et al. ${ }^{142}$ reported a MIP-SERS sensor for rapid detection and quantification of bitertanol in cucumbers and peaches. It should be noted that because of the relatively low detection performance of the portable instruments, the detection sensitivity and reproducibility are decreased. ${ }^{143}$ Thus, this application mode is more fit for an area not emphasizing detection sensitivity like rapid screening.

Biological Detection in the Microscopic Scale. At the current stage, MIP-SERS sensors are mainly used for qualitative and quantitative detection of small molecules in the environment and food analysis fields. With the continuous development of society, micro area detection of analytes and imaging in cells/tissues has aroused widespread attention in the field of biomedical analysis. Therefore, we will elaborate on the two aspects: micro area detection of analytes in cells/ tissues and cell/tissue imaging.

Nanoparticle-typed MIP-SERS sensors are applicable for detection of living cell and tissues via coincubation; however, the intracellular/microscale locations can hardly be controlled due to the random diffusion after entering living cells or tissues. ${ }^{144}$ Under this circumstance, researchers have developed a new application model to achieve the micro area detection of cells/tissues: needle MIP-SERS sensors. The sensor uses the noble metal coated needle as SERS substrates, and then the MIPs layer is prepared on the surface to form microprobe to specifically extract the analyte in living cells/ tissues. The key to implement this application mode is that the needle has a very small volume, enabling precise positioning of cells or subcellular and negligible damage to cells/ tissues. ${ }^{145-147}$ In addition, this application mode has high spatial and temporal resolution compared with traditional noble metal NPs. ${ }^{145}$ So, this application mode has attracted much attention from researchers. ${ }^{148-151}$ Based on PISA, Liu et al. prepared a needle MIP-SERS sensor (the size is about 1 $\mu \mathrm{m})$ for detecting ALP and AFP contents in single cells in vivo (Figure 9B). ${ }^{104}$ Target proteins can also be extended to other kinds of protein biomarkers or molecules. For example, this research group further applied the method to the detection of glucose and fructose in plant tissues. ${ }^{152}$ Accordingly, this sensor can be a versatile tool for a variety of important applications, such as disease diagnosis, pharmacological evaluation, and ecological analysis. If the needle MIP-SERS sensors are used in conjunction with the portable Raman spectrometer, real-time live detection will be achieved. Moreover, researchers should further extend the application model of MIP-SERS sensors to maximize the application ranges of MIP-SERS sensors.

It is well-known that SERS probes have the advantages of ultrahigh sensitivity, excellent light stability, multiplexing labeling ability, and biocompatibility. Therefore, SERS probes are often used as a noninvasive tool for cell/tissue imaging and cancer detection. ${ }^{3,153-156}$ Consequently, researchers have attempted to apply MIP-SERS sensors to the field of cell/ tissue imaging by preparing MIP-SERS tags. Compared with traditional SERS probes modified with antibodies as recognition units, MIP-SERS tags gain selectivity and with better designability and structural stability. Also, compared with laser scanning confocal microscopy, Raman spectroscopy can use ultraviolet to near-infrared (NIR) light as an excitation source, offering a high spatial resolution. ${ }^{55}$ Therefore, MIPSERS tags have great advantages in the field of cell/tissue imaging.

On the basis of previous researches in the boronate-affinity MIP-SERS sensors, Liu's group ${ }^{154}$ has prepared MIP-SERS tags with sialic acid (SA) as a template (Figure 10A, B). When the cells become cancerous, SA is overexpressed on the surface of cancer cells. Therefore, the probe is able to distinguish cancer cells/tissues. This is the first time that MIP-SERS tags have been used to image cancer cells and tissues on normal cells and tissues. ${ }^{154}$ In addition, the group has further proposed multifunctional MIP-SERS tags for recognition and NIR photothermal treatment of cancer. NIR laser irradiation on the MIP-SERS tags induces the localized hyperthermia effect, which could selectively inhibit/kill the cancer cells without affecting the surrounding healthy cells and tissues (Figure 10C). ${ }^{157}$ This boronate-affinity based MIP-SERS method is simple and easy to apply in a variety of biomarkers, indicating promising perspectives for cancer screening and treatment.

\section{CONCLUSIONS AND REMARKS}

As emerging optical probes, MIP-SERS sensors combine the advantage of excellent binding selectivity from MIPs with molecular recognition features and super detection sensitivity from SERS with fingerprint recognition characteristics. With elaborate structural designs on the interfaces between SERS substrates and MIPs, sensors of many structure types have been developed, which give full play to the properties of the two materials. MIP-SERS sensors have exhibited excellent detection performance toward various kinds of analytes in complex aqueous media, and on this basis they have also been successfully tested in some higher-level applications such as in situ fast analysis and early cancer diagnosis/treatment. We believe that MIP-SERS sensors will have better development in the future by learning from the latest research results of MIPs and SERS and by integrating more advanced sensing platforms such as microfluidics, ${ }^{97,133}$ which will further improve the detection quality and expand the application areas.

\section{AUTHOR INFORMATION}

\section{Corresponding Authors}

Jinhua Li - CAS Key Laboratory of Coastal Environmental Processes and Ecological Remediation, Research Center for Coastal Environmental Engineering and Technology, Yantai Institute of Coastal Zone Research and Center for Ocean MegaScience, Chinese Academy of Sciences, Yantai 264003, China; Email: jhli@yic.ac.cn

Yunqing Wang - CAS Key Laboratory of Coastal Environmental Processes and Ecological Remediation, Research Center for Coastal Environmental Engineering and Technology, Yantai Institute of Coastal Zone Research, Chinese Academy of Sciences, Yantai 264003, China; Email: yqwang@yic.ac.cn

Lingxin Chen - CAS Key Laboratory of Coastal Environmental Processes and Ecological Remediation, Research Center for Coastal Environmental Engineering and Technology, Yantai Institute of Coastal Zone Research, Chinese Academy of Sciences, Yantai 264003, China; School of Pharmacy, Binzhou Medical University, Yantai 264003, China; College of Chemistry and Chemical Engineering, Qufu Normal University, Qufu 273165, 
China; @orcid.org/0000-0002-3764-3515; Email: 1xchen@ yic.ac.cn

\section{Authors}

Xiaotong Guo - CAS Key Laboratory of Coastal Environmental Processes and Ecological Remediation, Research Center for Coastal Environmental Engineering and Technology, Yantai Institute of Coastal Zone Research, Chinese Academy of Sciences, Yantai 264003, China; University of Chinese Academy of Sciences, Beijing 100049, China

Maryam Arabi - CAS Key Laboratory of Coastal Environmental Processes and Ecological Remediation, Research Center for Coastal Environmental Engineering and Technology, Yantai Institute of Coastal Zone Research, Chinese Academy of Sciences, Yantai 264003, China; (1) orcid.org/0000-00022028-9572

Xiaoyan Wang - CAS Key Laboratory of Coastal Environmental Processes and Ecological Remediation, Research Center for Coastal Environmental Engineering and Technology, Yantai Institute of Coastal Zone Research, Chinese Academy of Sciences, Yantai 264003, China; School of Pharmacy, Binzhou Medical University, Yantai 264003, China

Complete contact information is available at:

https://pubs.acs.org/10.1021/acssensors.9b02039

\section{Notes}

The authors declare no competing financial interest.

\section{ACKNOWLEDGMENTS}

This work was financially supported by the Youth Innovation Promotion Association CAS (2017256), the National Natural Science Foundation of China (21876199, 21804010, 41776110, 81573393, 21976209), the Instrument Developing Project of the Chinese Academy of Sciences (YZ201662), the Science and Technology Development Plan of Shandong Province of China (2019GSF108047), the Technical Innovation Project of Instrument Function Development of the Chinese Academy of Sciences, the Chinese Academy of Sciences President's International Fellowship Initiative (2019PC0050), and the Taishan Scholar Project Special Funding (ts20190962).

\section{VOCABULARY}

MIP-SERS sensor, MIPs are used as specific sensing materials in SERS sensor, or SERS spectroscopy technique is employed for the measurement of vibrational characteristic signatures of the adsorbed compounds in MIPs layers, in which the MIPs as recognition elements can specifically bind target analytes and as transduction elements can generate Raman output signals for SERS detection; Electromagnetic enhancement, local electric field enhancement due to surface plasmon resonance; Chemical enhancement, the enhancement caused by the adsorption characteristics of the substance molecules on the metal substrate and the charge transfer between the molecules and the substrate; Hot spot, high-intensity local electric field existing in the interstices of noble metal nanoparticles; Epitope, surface domains composed of three to six amino acid residues of the macromolecule antigenic site; Boronateaffinity, the molecular interactions of the reversible covalent reaction between boronic acid ligands and cis-diol-containing compounds

\section{REFERENCES}

(1) Chen, L. X.; Fu, X. L.; Li, J. H. Ultrasensitive surface-enhanced Raman scattering detection of trypsin based on anti-aggregation of 4mercaptopyridine-functionalized silver nanoparticles: an optical sensing platform toward proteases. Nanoscale 2013, 5, 5905-5911.

(2) Schlucker, S. SERS microscopy: nanoparticle probes and biomedical applications. ChemPhysChem 2009, 10, 1344-1354.

(3) Wang, Y. Q.; Yan, B.; Chen, L. X. SERS tags: novel optical nanoprobes for bioanalysis. Chem. Rev. 2013, 113, 1391-1428.

(4) Doering, W. E.; Piotti, M. E.; Natan, M. J.; Freeman, R. G. SERS as a foundation for nanoscale, optically detected biological labels. Adv. Mater. 2007, 19, 3100-3108.

(5) McNay, G.; Eustace, D.; Smith, W. E.; Faulds, K.; Graham, D. Surface-enhanced Raman scattering (SERS) and surface-enhanced resonance Raman scattering (SERRS): A review of applications. Appl. Spectrosc. 2011, 65, 825-837.

(6) Schlucker, S. Surface-enhanced Raman spectroscopy: concepts and chemical applications. Angew. Chem., Int. Ed. 2014, 53, 47564795.

(7) Grubisha, D. S.; Lipert, R. J.; Park, H. Y.; Driskell, J.; Porter, M. D. Femtomolar detection of prostate-specific antigen: An immunoassay based on surface-enhanced Raman scattering and immunogold labels. Anal. Chem. 2003, 75, 5936-5943.

(8) Bantz, K. C.; Meyer, A. F.; Wittenberg, N. J.; Im, H.; Kurtulus, O.; Lee, S. H.; Lindquist, N. C.; Oh, S. H.; Haynes, C. L. Recent progress in SERS biosensing. Phys. Chem. Chem. Phys. 2011, 13, $11551-11567$.

(9) Wang, F.; Cao, S. Y.; Yan, R. X.; Wang, Z. W.; Wang, D.; Yang, H. F. Selectivity/specificity improvement strategies in surfaceenhanced Raman spectroscopy analysis. Sensors 2017, 17, 2689.

(10) Lee, H. K.; Lee, Y. H.; Koh, C. S. L.; Phan-Quang, G. C.; Han, X.; Lay, C. L.; Sim, H. Y. F.; Kao, Y.-C.; An, Q.; Ling, X. Y. Designing surface-enhanced Raman scattering (SERS) platforms beyond hotspot engineering: emerging opportunities in analyte manipulations and hybrid materials. Chem. Soc. Rev. 2019, 48, 731-756.

(11) Li, M.; Paidi, S. K.; Sakowski, E.; Preheim, S.; Barman, I. Ultrasensitive detection of hepatotoxic microcystin production from cyanobacteria using surface-enhanced Raman scattering immunosensor. ACS Sens. 2019, 4, 1203-1210.

(12) Wen, S. P.; Miao, X. R.; Fan, G. C.; Xu, T. T.; Jiang, L. P.; Wu, P.; Cai, C. X.; Zhu, J. J. Aptamer-conjugated Au nanocage $/ \mathrm{SiO}_{2}$ coreshell bifunctional nanoprobes with high stability and biocompatibility for cellular SERS imaging and near-infrared photothermal therapy. ACS Sens. 2019, 4, 301-308.

(13) Zhang, X.; Liu, S.; Song, X. L.; Wang, H. W.; Wang, J. F.; Wang, Y.; Huang, J. D.; Yu, J. H. Robust and universal SERS sensing platform for multiplexed detection of Alzheimer's disease core biomarkers using PAapt-AuNPs conjugates. ACS Sens. 2019, 4, $2140-2149$.

(14) Guerrini, L.; Garcia-Ramos, J. V.; Domingo, C.; SanchezCortes, S. Sensing polycyclic aromatic hydrocarbons with dithiocarbamate-functionalized Ag nanoparticles by surface-enhanced Raman scattering. Anal. Chem. 2009, 81, 953-960.

(15) Yuan, H. Z.; Ji, W.; Chu, S. W.; Liu, Q.; Qian, S. Y.; Guang, J. Y.; Wang, J. B.; Han, X. Y.; Masson, J. F.; Peng, W. Mercaptopyridinefunctionalized gold nanoparticles for fiber-optic surface plasmon resonance $\mathrm{Hg}^{2+}$ sensing. ACS Sens. 2019, 4, 704-710.

(16) Zeng, Y.; Wang, L. H.; Zeng, L. W.; Shen, A. G.; Hu, J. M. A label-free SERS probe for highly sensitive detection of $\mathrm{Hg}^{2+}$ based on functionalized Au@Ag nanoparticles. Talanta 2017, 162, 374-379.

(17) Xu, S.; Cao, X.; Zhou, Y. K. Polyvinylpyrrolidine-functionalized silver nanoparticles for SERS based determination of copper(II). Microchim. Acta 2019, 186, 562.

(18) Szlag, V. M.; Rodriguez, R. S.; He, J. Y.; Hudson-Smith, N.; Kang, H.; Le, N.; Reineke, T. M.; Haynes, C. L. Molecular affinity agents for intrinsic surface-enhanced Raman scattering (SERS) sensors. ACS Appl. Mater. Interfaces 2018, 10, 31825-31844.

(19) Sun, F.; Hung, H. C.; Sinclair, A.; Zhang, P.; Bai, T.; Galvan, D. D.; Jain, P.; Li, B. W.; Jiang, S. Y.; Yu, Q. M. Hierarchical zwitterionic 
modification of a SERS substrate enables real-time drug monitoring in blood plasma. Nat. Commun. 2016, 7, 13437.

(20) Lv, Y. Q.; Qin, Y. T.; Svec, F.; Tan, T. W. Molecularly imprinted plasmonic nanosensor for selective SERS detection of protein biomarkers. Biosens. Bioelectron. 2016, 80, 433-441.

(21) Chen, S. N.; Li, X.; Guo, Y.; Qi, J. Y. A Ag-molecularly imprinted polymer composite for efficient surface-enhanced Raman scattering activities under a low-energy laser. Analyst 2015, 140, 3239-3243.

(22) Wackerlig, J.; Lieberzeit, P. A. Molecularly imprinted polymer nanoparticles in chemical sensing -synthesis, characterisation and application. Sens. Actuators, B 2015, 207, 144-157.

(23) Ahmad, R.; Griffete, N.; Lamouri, A.; Felidj, N.; Chehimi, M. M.; Mangeney, C. Nanocomposites of gold nanoparticles@ molecularly imprinted polymers: chemistry, processing, and applications in sensors. Chem. Mater. 2015, 27, 5464-5478.

(24) Kumar, P.; Kim, K. H.; Deep, A. Recent advancements in sensing techniques based on functional materials for organophosphate pesticides. Biosens. Bioelectron. 2015, 70, 469-481.

(25) Irshad, M.; Iqbal, N.; Mujahid, A.; Afzal, A.; Hussain, T.; Sharif, A.; Ahmad, E.; Athar, M. M. Molecularly imprinted nanomaterials for sensor applications. Nanomaterials 2013, 3, 615-637.

(26) Chen, L. X.; Wang, X. Y.; Lu, W. H.; Wu, X. Q.; Li, J. H. Molecular imprinting: perspectives and applications. Chem. Soc. Rev. 2016, 45, 2137-2211.

(27) Diaz-Alvarez, M.; Turiel, E.; Martin-Esteban, A. Molecularly imprinted polymer monolith containing magnetic nanoparticles for the stir-bar sorptive extraction of thiabendazole and carbendazim from orange samples. Anal. Chim. Acta 2019, 1045, 117-122.

(28) Xu, Z. F.; Deng, P. H.; Li, J. H.; Tang, S. P.; Cui, Y. Modification of mesoporous silica with molecular imprinting technology: A facile strategy for achieving rapid and specific adsorption. Mater. Sci. Eng., C 2019, 94, 684-693.

(29) Bagheri, A. R.; Arabi, M.; Ghaedi, M.; Ostovan, A.; Wang, X. Y.; Li, J. H.; Chen, L. X. Dummy molecularly imprinted polymers based on a green synthesis strategy for magnetic solid-phase extraction of acrylamide in food samples. Talanta 2019, 195, 390400.

(30) Bitas, D.; Samanidou, V. Molecularly imprinted polymers as extracting media for the chromatographic determination of antibiotics in milk. Molecules 2018, 23, 316.

(31) Ncube, S.; Madikizela, L.; Cukrowska, E.; Chimuka, L. Recent advances in the adsorbents for isolation of polycyclic aromatic hydrocarbons (PAHs) from environmental sample solutions. TrAC, Trends Anal. Chem. 2018, 99, 101-116.

(32) Ansari, S.; Masoum, S. Molecularly imprinted polymers for capturing and sensing proteins: Current progress and future implications. TrAC, Trends Anal. Chem. 2019, 114, 29-47.

(33) Cao, Y. R.; Feng, T. Y.; Xu, J.; Xue, C. H. Recent advances of molecularly imprinted polymer-based sensors in the detection of food safety hazard factors. Biosens. Bioelectron. 2019, 141, 111447.

(34) Verma, R.; Gupta, B. D. Optical fiber sensor for the detection of tetracycline using surface plasmon resonance and molecular imprinting. Analyst 2013, 138, 7254-7263.

(35) Ma, P. Y.; Liang, F. H.; Sun, Y.; Jin, Y.; Chen, Y.; Wang, X. H.; Zhang, H. Q.; Gao, D. J.; Song, D. Q. Rapid determination of melamine in milk and milk powder by surface-enhanced Raman spectroscopy and using cyclodextrin-decorated silver nanoparticles. Microchim. Acta 2013, 180, 1173-1180.

(36) Kostrewa, S.; Emgenbroich, M.; Klockow, D.; Wulff, G. Surface-enhanced Raman scattering on molecularly imprinted polymers in water. Macromol. Chem. Phys. 2003, 204, 481-487.

(37) Wang, L. Z.; Xu, Y.; Tan, X. J.; Tapas, S.; Zhang, J. L. Aim and shoot: molecule-imprinting polymer coated $\mathrm{MoO}_{3}$ for selective SERS detection and photocatalytic destruction of low-level organic contaminants. RSC Adv. 2017, 7, 36201-36207.

(38) Li, H. J.; Wang, X. N.; Wang, Z. R.; Jiang, J. Q.; Qiao, Y.; Wei, M. B.; Yan, Y. S.; Li, C. X. A high-performance SERS-imprinted sensor doped with silver particles of different surface morphologies for selective detection of pyrethroids in rivers. New J. Chem. 2017, 41, $14342-14350$.

(39) Carrasco, S.; Benito-Pena, E.; Navarro-Villoslada, F.; Langer, J.; Sanz-Ortiz, M. N.; Reguera, J.; Liz-Marzan, L. M.; Moreno-Bondi, M. C. Multibranched gold-mesoporous silica nanoparticles coated with a molecularly imprinted polymer for label-free antibiotic surface enhanced Raman scattering analysis. Chem. Mater. 2016, 28, 79477954.

(40) Li, Y.; Wang, Y.; Wang, M. C.; Zhang, J. Y.; Wang, Q. W.; Li, H. J. A molecularly imprinted nanoprobe incorporating $\mathrm{Cu}_{2} \mathrm{O} @ \mathrm{Ag}$ nanoparticles with different morphologies for selective SERS based detection of chlorophenols. Microchim. Acta 2020, 187, 59.

(41) Chen, S. N.; Li, X.; Han, S.; Liu, J. H.; Zhao, Y. Y. Synthesis of surface-imprinted $\mathrm{Ag}$ nanoplates for detecting organic pollutants in water environments based on surface enhanced Raman scattering. RSC Adv. 2015, 5, 99914-99919.

(42) Reguera, J.; Langer, J.; de Aberasturi, D. J.; Liz-Marzan, L. M. Anisotropic metal nanoparticles for surface enhanced Raman scattering. Chem. Soc. Rev. 2017, 46, 3866-3885.

(43) Chen, L. X.; Choo, J. B. Recent advances in surface-enhanced Raman scattering detection technology for microfluidic chips. Electrophoresis 2008, 29, 1815-1828.

(44) Wang, Z. W.; Yan, R. X.; Liao, S. W.; Miao, Y. R.; Zhang, B.; Wang, F.; Yang, H. F. In situ reduced silver nanoparticles embedded molecularly imprinted reusable sensor for selective and sensitive SERS detection of Bisphenol A. Appl. Surf. Sci. 2018, 457, 323-331.

(45) Hu, R.; Tang, R.; Xu, J. Y.; Lu, F. Chemical nanosensors based on molecularly-imprinted polymers doped with silver nanoparticles for the rapid detection of caffeine in wastewater. Anal. Chim. Acta 2018, 1034, 176-183.

(46) Yin, W. M.; Wu, L.; Ding, F.; Li, Q.; Wang, P.; Li, J. J.; Lu, Z. C.; Han, H. Y. Surface-imprinted $\mathrm{SiO}_{2} @ \mathrm{Ag}$ nanoparticles for the selective detection of BPA using surface enhanced Raman scattering. Sens. Actuators, B 2018, 258, 566-573.

(47) Li, H. J.; Wang, X. N.; Wang, Z. R.; Wang, Y.; Dai, J. D.; Gao, L.; Wei, M. B.; Yan, Y. S.; Li, C. X. A polydopamine-based molecularly imprinted polymer on nanoparticles of type $\mathrm{SiO}_{2} @ \mathrm{rGO} @ \mathrm{Ag}$ for the detection of lambda-cyhalothrin via SERS. Microchim. Acta 2018, 185, 193.

(48) Kamra, T.; Zhou, T. C.; Montelius, L.; Schnadt, J.; Ye, L. Implementation of molecularly imprinted polymer beads for surface enhanced Raman detection. Anal. Chem. 2015, 87, 5056-5061.

(49) Bompart, M.; De Wilde, Y.; Haupt, K. Chemical nanosensors based on composite molecularly imprinted polymer particles and surface-enhanced Raman scattering. Adv. Mater. 2010, 22, 23432348.

(50) Shahar, T.; Sicron, T.; Mandler, D. Nanosphere molecularly imprinted polymers doped with gold nanoparticles for high selectivity molecular sensors. Nano Res. 2017, 10, 1056-1063.

(51) Li, H. J.; Jiang, J. Q.; Wang, Z. R.; Wang, X. N.; Liu, X. Q.; Yan, Y. S.; Li, C. X. A high performance and highly-controllable core-shell imprinted sensor based on the surface-enhanced Raman scattering for detection of R6G in water. J. Colloid Interface Sci. 2017, 501, 86-93.

(52) Kneipp, K.; Kneipp, H.; Itzkan, I.; Dasari, R. R.; Feld, M. S. Surface-enhanced non-linear Raman scattering at the single-molecule level. Chem. Phys. 1999, 247, 155-162.

(53) Cho, H.; Kumar, S.; Yang, D.; Vaidyanathan, S.; Woo, K.; Garcia, I.; Shue, H. J.; Yoon, Y.; Ferreri, K.; Choo, H. Surfaceenhanced Raman spectroscopy-based label-free insulin detection at physiological concentrations for analysis of Islet performance. ACS Sens. 2018, 3, 65-71.

(54) Luo, X. J.; Xing, Y. F.; Galvan, D. D.; Zheng, E. J.; Wu, P.; Cai, C. X.; Yu, Q. M. Plasmonic gold nanohole array for surface-enhanced Raman scattering detection of DNA methylation. ACS Sens. 2019, 4, $1534-1542$.

(55) Zong, C.; Xu, M. X.; Xu, L. J.; Wei, T.; Ma, X.; Zheng, X. S.; $\mathrm{Hu}$, R.; Ren, B. Surface-enhanced Raman spectroscopy for bioanalysis: reliability and challenges. Chem. Rev. 2018, 118, 49464980 . 
(56) Soldatova, A. V.; Ibrahim, M.; Olson, J. S.; Czernuszewicz, R. S.; Spiro, T. G. New light on NO bonding in Fe(III) Heme proteins from resonance Raman spectroscopy and DFT modeling. J. Am. Chem. Soc. 2010, 132, 4614-4625.

(57) Feng, M.; Tachikawa, H. Surface-enhanced resonance Raman spectroscopic characterization of the protein native structure. J. Am. Chem. Soc. 2008, 130, 7443-7448.

(58) Ferreira, N.; Marques, A.; Aguas, H.; Bandarenka, H.; Martins, R.; Bodo, C.; Costa-Silva, B.; Fortunato, E. Label-free nanosensing platform for breast cancer exosome profiling. ACS Sens. 2019, 4, 2073-2083.

(59) Ma, Y.; Promthaveepong, K.; Li, N. Chemical sensing on a single SERS particle. ACS Sens. 2017, 2, 135-139.

(60) Camacho, S. A.; Sobral, R. G.; Aoki, P. H. B.; Constantino, C. J. L.; Brolo, A. G. Zika immunoassay based on surface-enhanced Raman scattering nanoprobes. ACS Sens. 2018, 3, 587-594.

(61) Granger, J. H.; Porter, M. D. The case for human serum as a highly preferable sample matrix for detection of anthrax toxins. ACS Sens. 2018, 3, 2303-2310.

(62) Liu, P.; Liu, R. Y.; Guan, G. J.; Jiang, C. L.; Wang, S. H.; Zhang, Z. P. Surface-enhanced Raman scattering sensor for theophylline determination by molecular imprinting on silver nanoparticles. Analyst 2011, 136, 4152-4158.

(63) Kamra, T.; Xu, C. G.; Montelius, L.; Schnadt, J.; Wijesundera, S. A.; Yan, M. D.; Ye, L. Photoconjugation of molecularly imprinted polymer nanoparticles for surface-enhanced Raman detection of propranolol. ACS Appl. Mater. Interfaces 2015, 7, 27479-27485.

(64) Kantarovich, K.; Tsarfati, I.; Gheber, L. A.; Haupt, K.; Bar, I. Reading microdots of a molecularly imprinted polymer by surfaceenhanced Raman spectroscopy. Biosens. Bioelectron. 2010, 26, 809814.

(65) Kantarovich, K.; Tsarfati, I.; Gheber, L. A.; Haupt, K.; Bar, I. Writing droplets of molecularly imprinted polymers by nano fountain pen and detecting their molecular interactions by surface-enhanced Raman scattering. Anal. Chem. 2009, 81, 5686-5690.

(66) Ye, J.; Chen, Y.; Liu, Z. A boronate affinity sandwich assay: an appealing alternative to immunoassays for the determination of Glycoproteins. Angew. Chem., Int. Ed. 2014, 53, 10386-10389.

(67) Tu, X. Y.; Muhammad, P.; Liu, J.; Ma, Y. Y.; Wang, S. S.; Yin, D. Y.; Liu, Z. Molecularly imprinted polymer-based plasmonic immunosandwich assay for fast and ultrasensitive determination of trace Glycoproteins in complex samples. Anal. Chem. 2016, 88, 12363-12370.

(68) Riskin, M.; Ben-Amram, Y.; Tel-Vered, R.; Chegel, V.; Almog, J.; Willner, I. Molecularly imprinted Au nanoparticles composites on $\mathrm{Au}$ surfaces for the surface plasmon resonance detection of Pentaerythritol Tetranitrate, Nitroglycerin, and Ethylene Glycol Dinitrate. Anal. Chem. 2011, 83, 3082-3088.

(69) Marc, M.; Kupka, T.; Wieczorek, P. P.; Namiesnik, J. Computational modeling of molecularly imprinted polymers as a green approach to the development of novel analytical sorbents. TrAC, Trends Anal. Chem. 2018, 98, 64-78.

(70) Cai, X. Q.; Li, J. H.; Zhang, Z.; Yang, F. F.; Dong, R. C.; Chen, L. X. Novel $\mathrm{Pb}^{2+}$ ion imprinted polymers based on ionic interaction via synergy of dual functional monomers for selective solid-phase extraction of $\mathrm{Pb}^{2+}$ in water samples. ACS Appl. Mater. Interfaces 2014, $6,305-313$.

(71) Li, H. J.; Wang, Y.; Li, Y.; Qiao, Y.; Liu, L. H.; Wang, Q. W.; Che, G. High-sensitive molecularly imprinted sensor with multilayer nanocomposite for 2,6-dichlorophenol detection based on surfaceenhanced Raman scattering. Spectrochim. Acta, Part A 2020, 228, 117784 .

(72) Carboni, D.; Jiang, Y.; Malfatti, L.; Innocenzi, P. Selective detection of organophosphate through molecularly imprinted GERSactive hybrid organic-inorganic materials. J. Raman Spectrosc. 2018, 49, 189-197.

(73) Xing, R. R.; Wen, Y. R.; Dong, Y. R.; Wang, Y. J.; Zhang, Q.; Liu, Z. Dual molecularly imprinted polymer-based plasmonic immunosandwich assay for the specific and sensitive detection of protein biomarkers. Anal. Chem. 2019, 91, 9993-10000.

(74) Chen, S. N.; Dong, L. J.; Yan, M.; Dai, Z. X.; Sun, C. H.; Li, X. Rapid and sensitive biomarker detection using molecular imprinting polymer hydrogel and surface-enhanced Raman scattering. R. Soc. Open Sci. 2018, 5, 171488.

(75) Xiao, X. H.; Yan, K. L.; Xu, X. F.; Li, G. K. Rapid analysis of ractopamine in pig tissues by dummy-template imprinted solid-phase extraction coupling with surface-enhanced Raman spectroscopy. Talanta 2015, 138, 40-45.

(76) Kareuhanon, W.; Lee, V. S.; Nimmanpipug, P.; Tayapiwatana, C.; Pattarawarapan, M. Synthesis of molecularly imprinted polymers for nevirapine by dummy template imprinting approach. Chromatographia 2009, 70, 1531-1537.

(77) Chen, S. N.; Li, X.; Zhao, Y. Y.; Chang, L. M.; Qi, J. Y. High performance surface-enhanced Raman scattering via dummy molecular imprinting onto silver microspheres. Chem. Commun. 2014, 50, 14331-14333.

(78) Xu, S. F.; Lu, H. Z.; Li, J. H.; Song, X. L.; Wang, A. X.; Chen, L. X.; Han, S. B. Dummy molecularly imprinted polymers-capped CdTe quantum dots for the fluorescent sensing of 2,4,6-Trinitrotoluene. ACS Appl. Mater. Interfaces 2013, 5, 8146-8154.

(79) Singh, A. K.; Khan, S. A.; Fan, Z.; Demeritte, T.; Senapati, D.; Kanchanapally, R.; Ray, P. C. Development of a long-range surfaceenhanced Raman spectroscopy ruler. J. Am. Chem. Soc. 2012, 134, $8662-8669$.

(80) Holthoff, E. L.; Stratis-Cullum, D. N.; Hankus, M. E. A Nanosensor for TNT detection based on molecularly imprinted polymers and surface enhanced Raman scattering. Sensors 2011, 11, $2700-2714$.

(81) Beyazit, S.; Bui, B. T. S.; Haupt, K.; Gonzato, C. Molecularly imprinted polymer nanomaterials and nanocomposites by controlled/ living radical polymerization. Prog. Polym. Sci. 2016, 62, 1-21.

(82) Ashley, J.; Wu, K. Y.; Hansen, M. F.; Schmidt, M. S.; Boisen, A.; Sun, Y. Quantitative detection of trace level Cloxacillin in food samples using magnetic molecularly imprinted polymer extraction and surface-enhanced Raman spectroscopy nanopillars. Anal. Chem. 2017, $89,11484-11490$.

(83) Li, H. J.; Wang, X. N.; Wang, Z. R.; Jiang, J. Q.; Wei, M. B.; Zheng, J. H.; Yan, Y. S.; Li, C. X. Thermo-responsive molecularly imprinted sensor based on the surface-enhanced Raman scattering for selective detection of R6G in the water. Dalton Trans. 2017, 46, $11282-11290$.

(84) Liu, Z. G.; Gao, Y.; Jin, L.; Jin, H.; Xu, N.; Yu, X. Y.; Yu, S. H. Core-shell regeneration magnetic molecularly imprinted polymersbased SERS for sibutramine rapid detection. ACS Sustainable Chem. Eng. 2019, 7, 8168-8175.

(85) Li, J. F.; Zhang, Y. J.; Ding, S. Y.; Panneerselvam, R.; Tian, Z. Q. Core-shell nanoparticle-enhanced Raman spectroscopy. Chem. Rev. 2017, 117, 5002-5069.

(86) Wang, Y.; Li, H. J.; Wang, X. N.; Wang, Z. R.; Wang, M. C.; Li, Y.; Wang, Q. W. Preparation of a high-performance magnetic molecularly imprinted sensor for SERS detection of cyfluthrin in river. J. Raman Spectrosc. 2019, 50, 926-935.

(87) Man, T. T.; Lai, W.; Xiao, M. S.; Wang, X. W.; Chandrasekaran, A. R.; Pei, H.; Li, L. A versatile biomolecular detection platform based on photo-induced enhanced Raman spectroscopy. Biosens. Bioelectron. 2020, 147, 111742

(88) Lin, B. Y.; Kannan, P.; Qiu, B.; Lin, Z. Y.; Guo, L. H. On-spot surface enhanced Raman scattering detection of Aflatoxin B-1 in peanut extracts using gold nanobipyramids evenly trapped into the AAO nanoholes. Food Chem. 2020, 307, 125528.

(89) Kwan, P. P.; Banerjee, S.; Shariff, M.; Yusoff, F. M. Persistence of malachite green and leucomalachite green in red tilapia (Oreochromis hybrid) exposed to different treatment regimens. Food Control 2020, 108, 106866.

(90) Liu, Y. J.; Bao, J. J.; Zhang, L.; Chao, C.; Guo, J. J.; Cheng, Y. C.; Zhu, Y. J.; Xu, G. J. Ultrasensitive SERS detection of propranolol 
based on sandwich nanostructure of molecular imprinting polymers. Sens. Actuators, B 2018, 255, 110-116.

(91) Bagri, A.; Mattevi, C.; Acik, M.; Chabal, Y. J.; Chhowalla, M.; Shenoy, V. B. Structural evolution during the reduction of chemically derived graphene oxide. Nat. Chem. 2010, 2, 581-587.

(92) Chen, S. N.; Li, X.; Zhao, Y. Y.; Chang, L. M.; Qi, J. Y. Graphene oxide shell-isolated Ag nanoparticles for surface-enhanced Raman scattering. Carbon 2015, 81, 767-772.

(93) Ling, X.; Xie, L.; Fang, Y.; Xu, H.; Zhang, H.; Kong, J.; Dresselhaus, M. S.; Zhang, J.; Liu, Z. Can graphene be used as a substrate for Raman enhancement? Nano Lett. 2010, 10, 553-561.

(94) Yang, L. B.; Ma, L. A.; Chen, G. Y.; Liu, J. H.; Tian, Z. Q. Ultrasensitive SERS detection of TNT by imprinting molecular recognition using a new type of stable substrate. Chem. - Eur. J. 2010, $16,12683-12693$.

(95) Lin, X. L.; Wang, Y. Y.; Wang, L. N.; Lu, Y. D.; Li, J.; Lu, D. C.; Zhou, T.; Huang, Z. F.; Huang, J.; Huang, H. F.; Qiu, S. F.; Chen, R.; Lin, D.; Feng, S. Y. Interference-free and high precision biosensor based on surface enhanced Raman spectroscopy integrated with surface molecularly imprinted polymer technology for tumor biomarker detection in human blood. Biosens. Bioelectron. 2019, 143, 111599.

(96) Jahn, I. J.; Zukovskaja, O.; Zheng, X. S.; Weber, K.; Bocklitz, T. W.; Cialla-May, D.; Popp, J. Surface-enhanced Raman spectroscopy and microfluidic platforms: challenges, solutions and potential applications. Analyst 2017, 142, 1022-1047.

(97) Strehle, K. R.; Cialla, D.; Rosch, P.; Henkel, T.; Kohler, M.; Popp, J. A reproducible surface-enhanced Raman spectroscopy approach. Online SERS measurements in a segmented microfluidic system. Anal. Chem. 2007, 79, 1542-1547.

(98) Selvolini, G.; Marrazza, G. MIP-based sensors: promising new tools for cancer biomarker determination. Sensors 2017, 17, 718.

(99) Wu, L.; Qu, X. G. Cancer biomarker detection: recent achievements and challenges. Chem. Soc. Rev. 2015, 44, 2963-2997.

(100) Luo, X. L.; Davis, J. J. Electrical biosensors and the label free detection of protein disease biomarkers. Chem. Soc. Rev. 2013, 42, 5944-5962.

(101) Feng, J.; Li, X.; Cheng, H.; Huang, W. Y.; Kong, H. X.; Li, Y. Q.; Li, L. J. A boronate-modified molecularly imprinted polymer labeled with a SERS-tag for use in an antibody-free immunoassay for the carcinoembryonic antigen. Microchim. Acta 2019, 186, 774.

(102) Rissin, D. M.; Kan, C. W.; Campbell, T. G.; Howes, S. C.; Fournier, D. R.; Song, L.; Piech, T.; Patel, P. P.; Chang, L.; Rivnak, A. J.; Ferrell, E. P.; Randall, J. D.; Provuncher, G. K.; Walt, D. R.; Duffy, D. C. Single-molecule enzyme-linked immunosorbent assay detects serum proteins at subfemtomolar concentrations. Nat. Biotechnol. 2010, 28, 595-599.

(103) Su, K. L. M.; Zhang, Y.; Chen, S. N.; Zuo, S.; Ha, Y. S.; Dan, J. C.; Chen, W. F.; Sun, C. H.; Dai, Z. X.; Shi, X. T. Selectively encapsulating $\mathrm{Ag}$ nanoparticles on the surface of two-dimensional graphene for surface-enhanced Raman scattering. Appl. Surf. Sci. 2019, 492, 108-115.

(104) Liu, J.; Yin, D. Y.; Wang, S. S.; Chen, H. Y.; Liu, Z. Probing low-copy-number proteins in a single living cell. Angew. Chem., Int. Ed. 2016, 55, 13215-13218.

(105) Muhammad, P.; Tu, X. Y.; Liu, J.; Wang, Y. J.; Liu, Z. Molecularly imprinted plasmonic substrates for specific and ultrasensitive immunoassay of trace Glycoproteins in biological samples. ACS Appl. Mater. Interfaces 2017, 9, 12082-12091.

(106) Liu, Z.; He, H. Synthesis and applications of boronate affinity materials: from class selectivity to biomimetic specificity. Acc. Chem. Res. 2017, 50, 2185-2193.

(107) Wu, D. Y.; Li, J. F.; Ren, B.; Tian, Z. Q. Electrochemical surface-enhanced Raman spectroscopy of nanostructures. Chem. Soc. Rev. 2008, 37, 1025-1041.

(108) Li, W.; Zhang, Q.; Wang, Y. J.; Ma, Y. Y.; Guo, Z. C.; Liu, Z. Controllably prepared aptamer-molecularly imprinted polymer hybrid for high-specificity and high-affinity recognition of target proteins. Anal. Chem. 2019, 91, 4831-4837.
(109) Gast, M.; Sobek, H.; Mizaikoff, B. Advances in imprinting strategies for selective virus recognition a review. TrAC, Trends Anal. Chem. 2019, 114, 218-232.

(110) Rachkov, A.; Minoura, N. Recognition of oxytocin and oxytocin-related peptides in aqueous media using a molecularly imprinted polymer synthesized by the epitope approach. J. Chromatogr. A 2000, 889, 111-118.

(111) Rachkov, A.; Minoura, N. Towards molecularly imprinted polymers selective to peptides and proteins. The epitope approach. Biochim. Biophys. Acta, Protein Struct. Mol. Enzymol. 2001, 1544, 255266.

(112) Zhao, Y.; Sun, L.; Xi, M.; Feng, Q.; Jiang, C. Y.; Fong, H. Electrospun $\mathrm{TiO}_{2}$ nanofelt surface-decorated with Ag nanoparticles as sensitive and UV-cleanable substrate for surface enhanced Raman scattering. ACS Appl. Mater. Interfaces 2014, 6, 5759-5767.

(113) Jiang, X.; Li, X. L.; Jia, X. F.; Li, G. Z.; Wang, X.; Wang, G. Y.; Li, Z. S.; Yang, L. B.; Zhao, B. Surface-enhanced Raman scattering from synergistic contribution of metal and semiconductor in $\mathrm{TiO}_{2} /$ $\mathrm{MBA} / \mathrm{Ag}(\mathrm{Au})$ and $\mathrm{Ag}(\mathrm{Au}) / \mathrm{MBA} / \mathrm{TiO}_{2}$ assemblies. J. Phys. Chem. $\mathrm{C}$ 2012, 116, 14650-14655.

(114) Wang, Y. F.; Ruan, W. D.; Zhang, J. H.; Yang, B.; Xu, W. Q.; Zhao, B.; Lombardi, J. R. Direct observation of surface-enhanced Raman scattering in $\mathrm{ZnO}$ nanocrystals. J. Raman Spectrosc. 2009, 40, 1072-1077.

(115) Chen, T.; Xing, G. Z.; Zhang, Z.; Chen, H. Y.; Wu, T. Tailoring the photoluminescence of $\mathrm{ZnO}$ nanowires using $\mathrm{Au}$ nanoparticles. Nanotechnology 2008, 19, 435711.

(116) Zang, Y. S.; He, X.; Li, J.; Yin, J.; Li, K. Y.; Yue, C.; Wu, Z. M.; $\mathrm{Wu}$, S. T.; Kang, J. Y. Band edge emission enhancement by quadrupole surface plasmon-exciton coupling using direct-contact $\mathrm{Ag} / \mathrm{ZnO}$ nanospheres. Nanoscale 2013, 5, 574-580.

(117) Zhang, M. F.; Sun, H. R.; Chen, X.; Yang, J.; Shi, L.; Chen, T.; Bao, Z. Y.; Liu, J. Q.; Wu, Y. C. Highly efficient photoinduced enhanced Raman spectroscopy (PIERS) from plasmonic nanoparticles decorated 3D semiconductor arrays for ultrasensitive, portable, and recyclable detection of organic pollutants. ACS Sens. 2019, 4, 1670-1681.

(118) Morton, S. M.; Jensen, L. Understanding the molecule-surface chemical coupling in SERS. J. Am. Chem. Soc. 2009, 131, 4090-4098.

(119) Cheng, C. W.; Yan, B.; Wong, S. M.; Li, X. L.; Zhou, W. W.; Yu, T.; Shen, Z. X.; Yu, H. Y.; Fan, H. J. Fabrication and SERS performance of silver-nanoparticle-decorated $\mathrm{Si} / \mathrm{ZnO}$ nanotrees in ordered arrays. ACS Appl. Mater. Interfaces 2010, 2, 1824-1828.

(120) Zhang, B. H.; Wang, H. S.; Lu, L. H.; Ai, K. L.; Zhang, G.; Cheng, X. L. Large-area silver-coated silicon nanowire arrays for molecular sensing using surface-enhanced Raman spectroscopy. Adv. Funct. Mater. 2008, 18, 2348-2355.

(121) Li, H. J.; Wang, Z. R.; Wang, X. N.; Jiang, J. Q.; Zheng, J. H.; Yan, Y. S.; Li, C. X. High-performance composite imprinted sensor based on the surface enhanced Raman scattering for selective detection of 2,6-dichlorophenol in water. J. Raman Spectrosc. 2018, 49, 222-229.

(122) Zong, S. F.; Wang, Z. Y.; Yang, J.; Wang, C. L.; Xu, S. H.; Cui, Y. P. A SERS and fluorescence dual mode cancer cell targeting probe based on silica coated Au@Ag core-shell nanorods. Talanta 2012, 97, $368-375$.

(123) Prakash, J. Fundamentals and applications of recyclable SERS substrates. Int. Rev. Phys. Chem. 2019, 38, 201-242.

(124) Li, H. J.; Wang, Z. R.; Wang, X. N.; Jiang, J. Q.; Xu, Y. Q.; Liu, X. Q.; Yan, Y. S.; Li, C. X. Preparation of a self-cleanable molecularly imprinted sensor based on surface-enhanced Raman spectroscopy for selective detection of R6G. Anal. Bioanal. Chem. 2017, 409, 46274635.

(125) Zhong, Y.; Yu, X. Y.; Fu, W. Y.; Chen, Y. W.; Shan, G. Y.; Liu, Y. C. Colorimetric and Raman spectroscopic array for detection of hydrogen peroxide and glucose based on etching the silver shell of $\mathrm{Au} @ \mathrm{Ag}$ core-shell nanoparticles. Microchim. Acta 2019, 186, 802.

(126) Fraire, J. C.; Stremersch, S.; Bouckaert, D.; Monteyne, T.; De Beer, T.; Wuytens, P.; De Rycke, R.; Skirtach, A. G.; Raemdonck, K.; 
De Smedt, S.; Braeckmans, K. Improved label-free identification of individual exosome-like vesicles with Au@Ag nanoparticles as SERS substrate. ACS Appl. Mater. Interfaces 2019, 11, 39424-39435.

(127) Tang, L. J.; Li, S.; Han, F.; Liu, L. Q.; Xu, L. G.; Ma, W.; Kuang, H.; Li, A. K.; Wang, L. B.; Xu, C. L. SERS-active Au@Ag nanorod dimers for ultrasensitive dopamine detection. Biosens. Bioelectron. 2015, 71, 7-12.

(128) Lin, S.; Lin, X.; Han, S.; He, L.; Zhao, H. Y.; Zhang, J.; Hasi, W. L. J.; Wang, L. Width and length dependent SERS performance of core-shell Au@Ag nanorod self-assembled monolayers. J. Alloys Compd. 2019, 805, 318-326.

(129) Yin, H. J.; Chen, Z. Y.; Zhao, Y. M.; Lv, M. Y.; Shi, C. A.; Wu, Z. L.; Zheng, X.; Liu, L.; Wang, M. L.; Xu, H. J. Ag@Au core-shell dendrites: a stable, reusable and sensitive surface enhanced Raman scattering substrate. Sci. Rep. 2015, 5, 14502.

(130) Da Silva, A. G. M.; Rodrigues, T. S.; Slater, T. J. A.; Lewis, E. A.; Alves, R. S.; Fajardo, H. V.; Balzer, R.; da Silva, A. H. M.; de Freitas, I. C.; Oliveira, D. C.; Assaf, J. M.; Probst, L. F. D.; Haigh, S. J.; Camargo, P. H. C. Controlling size, morphology, and surface composition of AgAu nanodendrites in $15 \mathrm{~s}$ for improved environmental catalysis under low metal loadings. ACS Appl. Mater. Interfaces 2015, 7, 25624-25632.

(131) Liu, H. P.; Liu, T. Z.; Zhang, L.; Han, L.; Gao, C. B.; Yin, Y. D. Etching-free epitaxial growth of gold on silver nanostructures for high chemical stability and plasmonic activity. Adv. Funct. Mater. 2015, 25, 5435-5443.

(132) Zhang, J. W.; Winget, S. A.; Wu, Y. R.; Su, D.; Sun, X. J.; Xie, Z. X.; Qin, D.Ag@Au concave cuboctahedra: a unique probe for monitoring Au-catalyzed reduction and oxidation reactions by surfaceenhanced Raman spectroscopy. ACS Nano 2016, 10, 2607-2616.

(133) Zhang, T.; Sun, Y. Q.; Hang, L. F.; Li, H. L.; Liu, G. Q.; Zhang, X. M.; Lyu, X. J.; Cai, W. P.; Li, Y. Periodic porous alloyed Au$\mathrm{Ag}$ nanosphere arrays and their highly sensitive SERS performance with good reproducibility and high density of hotspots. ACS Appl. Mater. Interfaces 2018, 10, 9792-9801.

(134) Bai, T. L.; Sun, J. F.; Che, R. C.; Xu, L. N.; Yin, C. Y.; Guo, Z. $\mathrm{R}$; $\mathrm{Gu}, \mathrm{N}$. Controllable preparation of core-shell $\mathrm{Au}-\mathrm{Ag}$ nanoshuttles with improved refractive index sensitivity and SERS activity. ACS Appl. Mater. Interfaces 2014, 6, 3331-3340.

(135) Huang, J. F.; Zhu, Y. H.; Liu, C. X.; Zhao, Y. F.; Liu, Z. H.; Hedhili, M. N.; Fratalocchi, A.; Han, Y. Fabricating a homogeneously alloyed $\mathrm{AuAg}$ shell on $\mathrm{Au}$ nanorods to achieve strong, stable, and tunable surface plasmon resonances. Small 2015, 11, 5214-5221.

(136) Fan, M. K.; Lai, F. J.; Chou, H. L.; Lu, W. T.; Hwang, B. J.; Brolo, A. G. Surface-enhanced Raman scattering (SERS) from Au:Ag bimetallic nanoparticles: the effect of the molecular probe. Chem. Sci. 2013, 4, 509-515.

(137) Shen, W.; Lin, X.; Jiang, C. Y.; Li, C. Y.; Lin, H. X.; Huang, J. T.; Wang, S.; Liu, G. K.; Yan, X. M.; Zhong, Q. L.; Ren, B. Reliable quantitative SERS analysis facilitated by Core-Shell nanoparticles with embedded internal standards. Angew. Chem., Int. Ed. 2015, 54, 73087312.

(138) Cho, W. J.; Kim, Y.; Kim, J. K. Ultrahigh-density array of silver nanoclusters for SERS substrate with high sensitivity and excellent reproducibility. ACS Nano 2012, 6, 249-255.

(139) Lin, D. D.; Wu, Z. L.; Li, S. J.; Zhao, W. Q.; Ma, C. J.; Wang, J.; Jiang, Z. M.; Zhong, Z. Y.; Zheng, Y. B.; Yang, X. J. Large-area Aunanoparticle-functionalized $\mathrm{Si}$ nanorod arrays for spatially uniform surface-enhanced Raman spectroscopy. ACS Nano 2017, 11, 14781487.

(140) Yokota, Y.; Ueno, K.; Misawa, H. Highly controlled surfaceenhanced Raman scattering chips using nanoengineered gold blocks. Small 2011, 7, 252-258.

(141) Xue, J. Q.; Li, D. W.; Qu, L. L.; Long, Y. T. Surface-imprinted core-shell $\mathrm{Au}$ nanoparticles for selective detection of bisphenol A based on surface-enhanced Raman scattering. Anal. Chim. Acta 2013, $777,57-62$.

(142) Cao, X. L.; Zhao, F. N.; Jiang, Z. J.; Hong, S. H.; Zhang, C.; She, Y. X.; Jin, F.; Jin, M. J.; Wang, J. Rapid analysis of bitertanol in agro-products using molecularly imprinted polymers-surface-enhanced Raman spectroscopy. Food Anal. Methods 2018, 11, 14351443.

(143) Deidda, R.; Sacre, P. Y.; Clavaud, M.; Coic, L.; Avohou, H.; Hubert, P.; Ziemons, E. Vibrational spectroscopy in analysis of pharmaceuticals: critical review of innovative portable and handheld NIR and Raman spectrophotometers. TrAC, Trends Anal. Chem. 2019, 114, 251-259.

(144) Zhu, H.; Lussier, F.; Ducrot, C.; Bourque, M. J.; Spatz, J. P.; Cui, W. L.; Yu, L.; Peng, W.; Trudeau, L. E.; Bazuin, C. G.; Masson, J. F. Block copolymer brush layer-templated gold nanoparticles on nanofibers for surface-enhanced Raman scattering optophysiology. ACS Appl. Mater. Interfaces 2019, 11, 4373-4384.

(145) Yu, R. J.; Ying, Y. L.; Gao, R.; Long, Y. T. Confined nanopipette sensing: from single molecules, single nanoparticles, to single cells. Angew. Chem., Int. Ed. 2019, 58, 3706-3714.

(146) Hanif, S.; Liu, H. L.; Ahmed, S. A.; Yang, J. M.; Zhou, Y.; Pang, J.; Ji, L. N.; Xia, X. H.; Wang, K. Nanopipette-based SERS aptasensor for subcellular localization of cancer biomarker in single cells. Anal. Chem. 2017, 89, 9911-9917.

(147) Wang, W. K.; Zhao, F.; Li, M. Z.; Zhang, C. P.; Shao, Y. H.; Tian, Y. A SERS optophysiological probe for the real-time mapping and simultaneous determination of the carbonate concentration and $\mathrm{pH}$ value in a live mouse brain. Angew. Chem., Int. Ed. 2019, 58, 5256-5260.

(148) Lussier, F.; Brule, T.; Vishwakarma, M.; Das, T.; Spatz, J. P.; Masson, J. F. Dynamic-SERS optophysiology: a nanosensor for monitoring cell secretion events. Nano Lett. 2016, 16, 3866-3871.

(149) Yang, J. M.; Pan, Z. Q.; Qin, F. F.; Chen, M.; Wang, K.; Xia, X. H. An in situ SERS study of ionic transport and the Joule heating effect in plasmonic nanopores. Chem. Commun. 2018, 54, 1323613239.

(150) Niu, J. J.; Schrlau, M. G.; Friedman, G.; Gogotsi, Y. Carbon nanotube-tipped endoscope for in situ intracellular surface-enhanced Raman spectroscopy. Small 2011, 7, 540-545.

(151) Nguyen, T. D.; Song, M. S.; Ly, N. H.; Lee, S. Y.; Joo, S. W. Nanostars on nanopipette tips: a Raman probe for quantifying oxygen levels in hypoxic single cells and tumours. Angew. Chem., Int. Ed. 2019, $58,2710-2714$.

(152) Muhammad, P.; Liu, J.; Xing, R. R.; Wen, Y. R.; Wang, Y. J.; Liu, Z. Fast probing of glucose and fructose in plant tissues via plasmonic affinity sandwich assay with molecularly-imprinted extraction microprobes. Anal. Chim. Acta 2017, 995, 34-42.

(153) Zavaleta, C.; de la Zerda, A.; Liu, Z.; Keren, S.; Cheng, Z.; Schipper, M.; Chen, X.; Dai, H.; Gambhir, S. S. Noninvasive Raman spectroscopy in living mice for evaluation of tumor targeting with carbon nanotubes. Nano Lett. 2008, 8, 2800-2805.

(154) Yin, D. Y.; Wang, S. S.; He, Y. J.; Liu, J.; Zhou, M.; Ouyang, J.; Liu, B. R.; Chen, H. Y.; Liu, Z. Surface-enhanced Raman scattering imaging of cancer cells and tissues via sialic acid-imprinted nanotags. Chem. Commun. 2015, 51, 17696-17699.

(155) Qian, X. M.; Peng, X. H.; Ansari, D. O.; Yin-Goen, Q.; Chen, G. Z.; Shin, D. M.; Yang, L.; Young, A. N.; Wang, M. D.; Nie, S. M. In vivo tumor targeting and spectroscopic detection with surfaceenhanced Raman nanoparticle tags. Nat. Biotechnol. 2008, 26, 83-90.

(156) Zavaleta, C. L.; Smith, B. R.; Walton, I.; Doering, W.; Davis, G.; Shojaei, B.; Natan, M. J.; Gambhir, S. S. Multiplexed imaging of surface enhanced Raman scattering nanotags in living mice using noninvasive Raman spectroscopy. Proc. Natl. Acad. Sci. U. S. A. 2009, 106, 13511-13516.

(157) Yin, D. Y.; Li, X. L.; Ma, Y. Y.; Liu, Z. Targeted cancer imaging and photothermal therapy via monosaccharide-imprinted gold nanorods. Chem. Commun. 2017, 53, 6716-6719.

(158) Xie, Y. F.; Zhao, M. Y.; Hu, Q.; Cheng, Y. L.; Guo, Y. H.; Qian, H.; Yao, W. R. Selective detection of chloramphenicol in milk based on a molecularly imprinted polymer-surface-enhanced Raman spectroscopic nanosensor. J. Raman Spectrosc. 2017, 48, 204-210. 
(159) Chang, L. M.; Ding, Y.; Li, X. Surface molecular imprinting onto silver microspheres for surface enhanced Raman scattering applications. Biosens. Bioelectron. 2013, 50, 106-110.

(160) Guo, Y.; Kang, L. L.; Chen, S. N.; Li, X. High performance surface-enhanced Raman scattering from molecular imprinting polymer capsulated silver spheres. Phys. Chem. Chem. Phys. 2015, 17, 21343-21347.

(161) Ren, X.; Cheshari, E. C.; Qi, J. Y.; Li, X. Silver microspheres coated with a molecularly imprinted polymer as a SERS substrate for sensitive detection of bisphenol A. Microchim. Acta 2018, 185, 242. 